\title{
Occupant Productivity and Office Indoor Environment Quality: A Review of the Literature
}

\begin{abstract}
The purpose of this paper is to review the existing literature to draw an understanding of the relationship between indoor environmental quality and occupant productivity in an office environment. The study reviews over 300 papers from 67 journals, conference articles and books focusing on indoor environment, occupant comfort, productivity and green buildings. It limits its focus to the physical aspects of an office environment. The literature outlines eight Indoor Environmental Quality (IEQ) factors that influence occupant productivity in an office environment. It also discusses different physical parameters under each of the IEQ factors. It proposes a conceptual model of different factors affecting occupant productivity. The study also presents a review of the data collection methods utilised by the research studies that aim to investigate the relationship between IEQ and occupant productivity. The study presents a comprehensive discussion and analysis of different IEQ factors that affect occupant productivity. The paper provides a concise starting point for future researchers interested in the area of indoor environmental quality.
\end{abstract}

Keywords: occupant productivity, workplace satisfaction, indoor environment quality, occupant comfort

Paper type: Literature review

\subsection{Introduction}

Humans spend most of their time indoors, and the majority of the world's population lives in urban areas and work in an office environment (ASHRAE, 1993). There has been a significant global shift in the economy from the manufacturing sector towards the service and knowledge-based sectors which operate in indoor office environments (Haynes, 2008b, World Green Building Council, 2014). Hence, it is becoming important to understand the indoor office environment and the effect it has on occupant productivity. An office environment has a high level of influence on its occupants' productivity (Leaman and Bordass, 1999, Frontczak et al., 2012, Roelofsen, 2002, Mawson, 2002, Van der Voordt, 2004). Past studies on sustainable buildings postulate that green design strategies and technologies enhance the indoor workplace environment. Such strategies/technologies enable the creation of an environment which favours occupants' comfort and performance in both newly built and retrofitted buildings (Romm and Browning, 1994). The majority of the building stock that will exist in 2050 has already been built (2009). Thus, there is a need to investigate the quality of the indoor workplace environment and its relationship to occupant productivity. This paper establishes the state-of-the-art on environmental factors that influence occupant productivity in the office environment. It also highlights and discusses various occupant productivity measurement methods used in indoor environment research studies. This research will help construction industry professionals improve the designs that allow better operation of office buildings along with improving the productivity of the occupants. 


\subsection{Background}

The research on the direct and indirect effects of indoor environment quality on its occupants' productivity can be traced back to 1920s when Maslow, as well as Vernon \& Bedford published their work on the workplace environment and needs (Maslow, 1943, Vernon and Bedford, 1926, Vernon and Bedford, 1930). Herzberg (1966) and Heschong (1979) were early researchers who highlighted the influence of the indoor physical environment on its occupants' productivity in a workplace environment. Later, researchers stressed on the degree of influence of the built environment on its occupants' productivity. Research studies have provided evidence on the impact of the indoor environment on an organisation's operational expenses (Romm and Browning, 1994, Leaman and Bordass, 1999, Oseland, 1999, Heerwagen, 2000, Brill et al., 1985, Marans and Yan, 1989). The operational cost of an organisation is divided into personnel costs, material costs, financial costs and building related cost (Feige et al., 2013). In a study, it was seen that 25 years of companies' operational costs include around an 85 percent share of personnel costs (CABE, 2005). Other studies report that employees' annual salaries exceed the building operation and rental costs by a factor of up to 25 (Clements-Croome, 2000, Fisk, 2000a). A marginal change in occupants' performance can produce a massive impact on a company's operational costs. Research focusing on the USA estimated that improved work efficiency nationally could yield up to US\$12-125 billion yearly (1996 US\$ value) (Fisk, 2000a). A nationwide survey-based study using professionals from different sectors in the UK indicated that a good office environment can help to increase productivity by up to $20 \%$, equivalent to $£ 135$ bn per year (Wheeler and Almeida, 2006, Wheeler et al., 2006, Clements-Croome, 2015). The UK Centre for Mental Health coined the term 'presenteeism'. It refers to employees who are present at work but work with reduced productivity. Presenteeism plays a significant part in the reduced productivity within the built environment sector. It leads to loss of $£ 15$ billion per year in the UK (2011). The indoor environment influences the health and well-being of the occupants. Healthy buildings lead to more flourishing and happy inhabitants (Clements-Croome, 2013, Mendell et al., 2002). It is the moral responsibility of the built environment industry to deliver a built environment that is conducive to its occupants and promotes their health and well-being rather than providing buildings merely fit for survival. Efficient and conducive workplaces help to reduce employee absenteeism, reduce staff turnover, and increase occupant productivity and satisfaction, thus increasing the perceived health and well-being of their occupants (US Green Building Council, 2004, McGraw-Hill Construction, 2014). All this evidence highlights the impact of indoor environment quality on employee productivity and emphasises the importance of understanding Indoor Environment Quality (IEQ) and its effects on occupants' productivity.

The rest of this paper is divided into five sections. The first section describes the methodology of the study. It is followed by a section on literature review on occupant productivity. It reviews the relationship between green buildings and occupant productivity. An elaborate investigation of the scientific studies on occupant comfort and productivity in the built environment leads to the eight Indoor Environment Quality (IEQ) factors that affect occupant comfort and productivity. It reviews the relationship between each IEQ factor and occupant productivity. The third section provides an overview of the data collection methods used in the studies investigated in the literature review. It describes different methods of data collection that can be used for measuring the impact of Indoor Environment Quality on occupant productivity. A discussion section follows to discuss all the IEQ factors. Each factor is discussed individually along with the associated measurement technique that can be used to define the relationship between occupant productivity and the respective IEQ factor. The last section presents the conclusion of the study. 


\subsection{Methodology}

The study was developed using a wide-ranging literature review looking at journal articles, conference articles and books to establish a firm base for the research findings. The study followed a four step process to identify, collect and classify the literature

1. In step 1, the keywords for the research were identified. The aim of the research was to determine the impact of Indoor Environment Quality on occupant productivity in an office environment. The keywords for the search were: occupant productivity, workplace satisfaction, indoor environment quality, occupant comfort, thermal comfort, indoor air quality, office layout, and occupant satisfaction.

2. The primary emphasis of the research was to identify and collect evidence on different IEQ factors' impact on occupant productivity. The authors used the University library's online search engine and Google Scholar, Science Direct and Elsevier for the literature search using the keywords defined in step 1.

3. After reviewing the initial group of papers, the research team looked at the bibliographies of the downloaded papers to look for more relevant papers.

4. The final step involved a classification of the literature based on the following two aspects:

a) Year of Publication (1926-2015)

Articles were analysed according to the year of publication to draw an overall picture of the topic's research and development in the field of the built environment. The literature reviewed ranged from the 1920s to 2015.

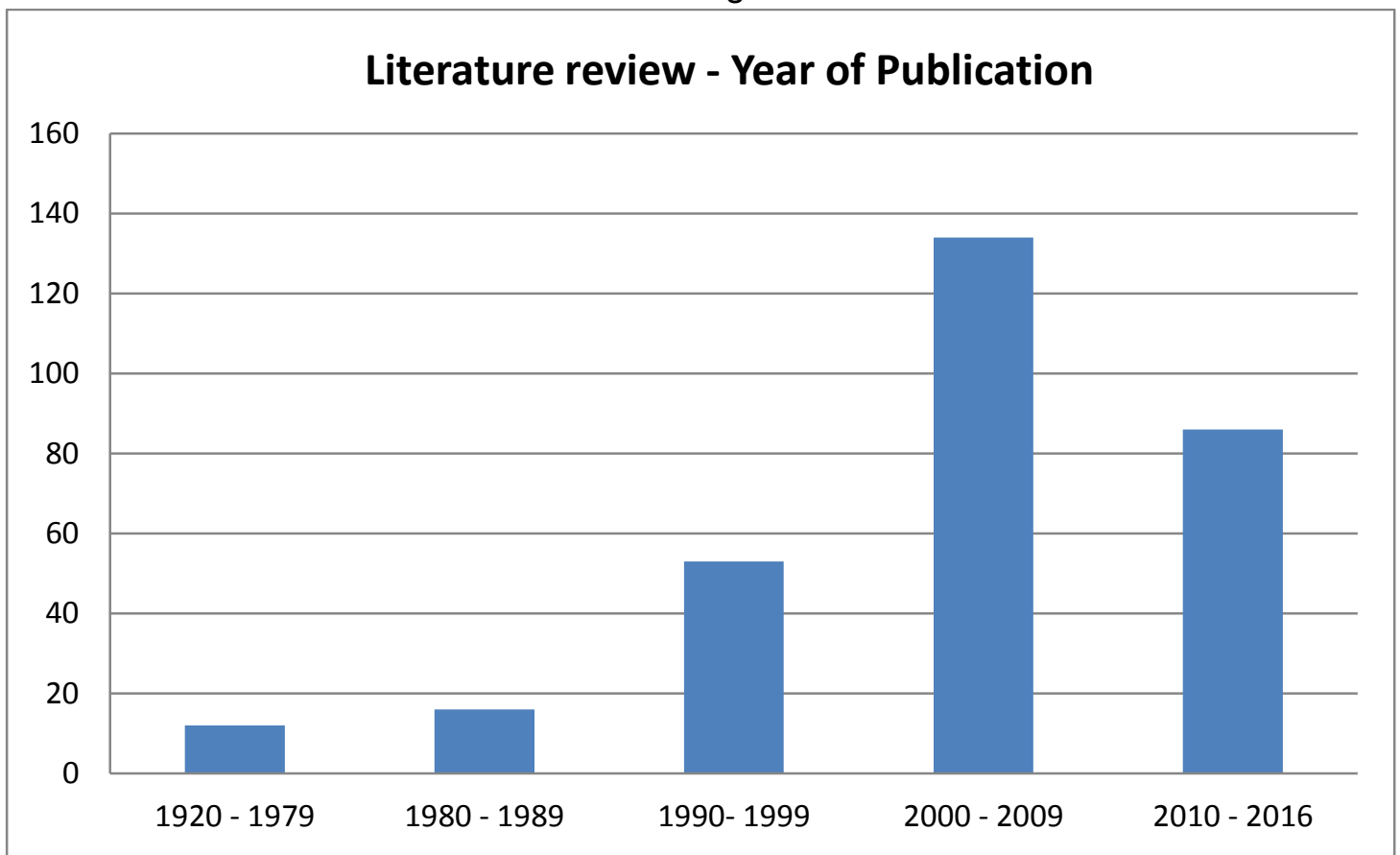

Figure 1 - The years of publication for the publications used in the study

b) Journal classification

The literature search collected papers from more than 80 journals and magazines via the online research tools. Table 1 presents a list of 67 key journals that were accessed. 


\section{Key journals used in the literature research}

1. Advances in Building Energy Research, Taylor \& Francis online

2. American Journal of Applied Science, Science Publications

3. American Journal of Biochemistry and Biotechnology, Science

4. Annual Review of Energy and the Environment, UC Berkeley

5. Applied Acoustics, Elsevier

6. Applied Energy, Elsevier

7. Applied Ergonomics, Elsevier

8. Applied Thermal Engineering, Elsevier

9. Architectural Engineering and Design Management, Taylor \& Francis

10. Architectural Lighting (Magazine), Hanley wood media

11. Architectural Science Review, Taylor \& Francis

12. Archives of Internal Medicine, JAMA

13. ASCE International Workshop on Computing in Civil Engineering, American Society of Civil Engineers

14. Atmospheric Environment, Elsevier

15. Automation in Construction, Elsevier

16. British journal of industrial medicine, JSTOR

17. British medical bulletin, Oxford

18. Building and Environment, Elsevier

19. Building Research \& Information, Taylor and Francis

20. Building Research and Practice, Taylor and Francis online

21. Center for the Built Environment; UC Berkeley

22. CIBSE Journal

23. Climate research journal

24. Color Research \& Application, Wiley online

25. Construction Economics and Building, UTS ePRESS

26. Energy and Building, Elsevier

27. Energy and the Environment

28. Energy Journal, Elsevier

29. Environment and Behavior, SAGE

30. Environmental science \& technology, ACS

31. Environmental Science and Pollution Research, Springer

32. Ergonomics, Taylor and Francis

33. Facilities, Emerald

34. HVAC\&R Research, Taylor \& Francis

35. Indoor and Built Environment, SAGE

36. Intelligent Buildings International, Taylor \& Francis

37. International Journal of engineering Research and Technology

38. International Journal of Construction Education and Research, Taylor \& Francis

39. International Journal of Environmental Research and Public Health, MDPI

40. International Journal of Hygiene and Environmental Health, Elsevier

41. International journal of Indoor Environment and Health, Wiley online

42. International Journal of Low-Carbon Technologies, Oxford University Press

43. Journal of Architectural and Planning Research, JSTOR

44. Journal of Architectural Engineering, ASCE

45. Journal of Corporate Real Estate, Emerald

46. Journal of Engineering, Design and Technology, Emerald

47. Journal of Environmental Psychology, Elsevier

48. Journal of Facilities Management, Emerald

49. Journal of Geophysical Research, AGU

50. Journal of Property Investment \& Finance, Emerald 


\author{
51. Journal of Sustainable Real Estate \\ 52. Journal of Thermal Biology, Pergamon \\ 53. LEUKOS: The Journal of the Illuminating Engineering Society of North America, \\ Taylor and Francis online \\ 54. Lighting Design and Application, BSRIA \\ 55. Lighting Research and Technology, SAGE \\ 56. Occupational Medicine, Oxford journal \\ 57. Perceptual and Motor Skills, SAGE \\ 58. Physics, Elsevier \\ 59. Psychological Science, Sage \\ 60. Renewable and Sustainable Energy Reviews, Elsevier \\ 61. Renewable Energy, Elsevier \\ 62. Science and Technology for the Built Environment, Taylor \& Francis \\ 63. Social and Behavioral Sciences, Elsevier \\ 64. Solar energy, Elsevier \\ 65. Sustainable Cities and Society, Elsevier \\ 66. Technology in Society, Elsevier \\ 67. The Journal of the Acoustical Society of America, ASA
}

Table 1 - Key Journals used in paper collection in the literature search

Following these steps the review of the literature was developed which is presented in the following sections.

\title{
4.0 Green Buildings and Occupant Productivity
}

Several researchers have discussed the relationship between the performance of buildings and their occupants' productivity (Heerwagen, 2000, Romm and Browning, 1994, ClementsCroome, 2015, US Green Building Council, 2004, Miller et al., 2009). Green building councils across the world acknowledge the importance of occupant productivity. The United States Green Building Council's (USGBC) credit based green building rating system, the Leadership in Energy and Environmental Design (LEED) and Japan's CASBEE (Comprehensive Assessment System for Building Environmental Efficiency) include Indoor Environmental Quality (IEQ) as one of their measurement categories. In the UK, the Building Research Establishment's BREAAM (Building Research Establishment Environmental Assessment Method) includes various thermal, acoustic and air quality measures in its health and well-being category (Potbhare et al., 2009). The literature reviewed suggests that green buildings help to increase occupant productivity (Singh et al., 2010, Abbaszadeh et al., 2006, Romm and Browning, 1994, Heerwagen, 2000). A study of 500 LEED rated green buildings proved that a high-performance building or 'healthy' building helps to reduce absenteeism, increases occupant productivity and improves employee well-being (Miller et al., 2009). Green buildings decrease operational costs by reducing energy costs and increasing occupant productivity (Gabay et al., 2014, Clements-Croome, 2004b). Green buildings have a higher built asset value as compared to non-green buildings and they contribute to spreading awareness concerning the environment and efficient building operations (Roberts and Newell, 2009, Clements-Croome, 2004a, Clements-Croome, 2004b, Clements-Croome, 2015). Overall, there is a sense of awareness about the significance of IEQ's impact on occupant productivity. However, there is a lack of direct focus in green building guidelines to address this aspect and increase green buildings' performance in occupant productivity dimension (Potbhare et al., 2009). LEED green building rating system has indoor environment quality category that focuses on thermal comfort, indoor air quality, lighting and daylighting, quality of views, lighting and daylighting and acoustic performance. These criteria affect occupant comfort and productivity but these are mainly related to the mechanical aspects of indoor environment quality assessment. The main categories in LEED rating system are also set up focussing on the engineering aspect 
of the buildings such as site usage, energy, water conservation, building material components, and recycling of waste materials (Lee and Guerin, 2009). There is no direct effort to cater occupant satisfaction and promote occupant productivity. Similarly, BREEAM has health and wellbeing category outlining issues such as visual comfort, indoor air quality, thermal comfort, acoustic performance, private space, accessibility, hazards, water quality, and safe contaminants in laboratories (Lee, 2013). Majority of these issues/factors contribute in occupant productivity. However, BREAAM doesn't explicitly relate these issues to occupant productivity. Most of the occupant health and comfort parameters could result in higher occupant productivity. However, this might not be the case in every situation. Research states that it is not necessary that optimum thermal comfort and optimum productivity coincides within acceptable thermal comfort range (Fisk, 2000b). There is an opportunity to analyse indoor environment quality criteria in various international green building guidelines. These criteria can be updated to focus on occupant health and productivity rather than just focusing on building performance.

Productivity is defined as the ratio of output to input (Oseland and Bartlett, 1999). The definition of productivity can vary, depending on the context and content of the input and output. In organisational operational terms, productivity can be described as the ratio of company turnover to employee cost (Oseland and Bartlett, 1999). In the case of office environments, performance/productivity can be measured using different criteria such as individual performance, team performance and organisational performance (Heerwagen, 2000, Feige et al., 2013, Oseland, 1999). In case of built environment, the input is the operational cost of a building and output is the building's operational performance. The output of an office building should include both building and occupant performance to give a more comprehensive picture. This paper explores indoor environment quality factors that have impact on productivity. It also highlights the nature and significance of the impact of these IEQ factors. Four main aspects that affect human productivity in an organisational working environment are personal, social, organisational and environmental factors. These factors influence the overall productivity of the employees. The level of influence and the inter-relationships of these individual factors is still unclear (Clements-Croome, 2006). A favourable environmental setting for occupants reduces the number of complaints and absenteeism and enhances productivity (Clements-Croome, 2000, Clements-Croome, 2006, Lorsch and Abdou, 1994, Bordass et al., 1993, Tse and So, 2007, Zhai et al., 2013). An office environment is considered as a healthy indoor environment when 80 percent of its occupants are satisfied with the environmental settings (ASHRAE Standard, 2004). Occupants' satisfaction with the indoor environment is directly related to the amount of comfort they experience within the environment (Frontczak et al., 2012, Choi et al., 2009, Brager and Baker, 2009, Heerwagen, 2000). Employees' comfort with the environment has a direct impact on their workplace satisfaction which highly influence their productivity.

Comfort is defined by an absence of unpleasant sensations, thus providing positive effects on well-being. It is subjective in nature and varies from person to person. There are different types of comfort in an office environment. It includes physical comfort (air quality, climate, noise), functional comfort (disturbances, interruptions, distance from work, resources) and psychological comfort (privacy, territoriality) (Feige et al., 2013). Comfort in an office environment can also be affected by physiological components, psychological components and physical environmental conditions (Oseland, 1999). Oseland suggests that physical environmental conditions can be broken down into physical conditions (temperature, light, noise, air quality), space (plan, layout and privacy), ergonomics (workstation and controls), and aesthetics (colour and quality). Overall comfort is an outcome of personal health and mood, in addition to functional as well as environmental factors (Leaman and Bordass, 1999, Clements-Croome, 2006). Researchers suggest that the behavioural environment, which comprises different behaviour and social dimensions in a workplace, affects overall occupant comfort (Haynes, 2007a, Fleming, 2004). Behavioural and social aspects such as privacy, collaboration, interaction and distraction are subjective and influence occupants' comfort (Brenner and Cornell, 1994, Fleming, 2004, Heerwagen et al., 2004, Ward and Holtham, 
2000, Haynes, 2007a, Haynes, 2007b). Haynes emphasises that the behavioural environment is an integrated dimension of an office environment, and it affects occupants' behaviour and the social environments which are created and evolved by office workers. Haynes (2007a) proposed a theoretical framework, suggesting that office occupiers and work patterns influence the physical and behavioural components constituting the office environment, and both have a collective impact on office productivity. He concludes that office layout and comfort are part of the physical environment, while distraction and interaction are part of the behavioural environment (Haynes, 2007a, Haynes, 2007b, Haynes, 2008a). The definition of comfort in the literature has a broad theoretical spectrum ranging from physical comfort and personal health to social psychology. This paper limits the focus to the physical comfort that directly relates to the Indoor Environmental Quality (IEQ) of a workplace.

The study identifies eight physical factorswhich affect occupant satisfaction and productivity in an office environment based on the findings in the previous literature:

- Indoor Air Quality and Ventilation (Vernon and Bedford, 1926, Wargocki et al., 2000, Fanger, 1988, Fisk et al., 2012)

- Thermal Comfort (Fanger, 1970, De Dear et al., 1997, Tanabe et al., 2007, Djongyang et al., 2010, Lan et al., 2011)

- Lighting and Daylighting (Hopkinson et al., 1966, Alrubaih et al., 2013, L Edwards, 2000, Sivaji et al., 2013)

- Noise and Acoustics (Sundstrom et al., 1994, Banbury and Berry, 2005, Mui and Wong, 2006)

- Office Layout (Brill et al., 1985, Laing et al., 1998, CABE, 2005, Haynes, 2009)

- Biophilia and Views (Heerwagen and Orians, 1984, Grinde and Patil, 2009, Heerwagen, 2009, Bright, 2012)

- Look and Feel (Mahnke, 1996, Kwallek et al., 1988, Ou et al., 2004, World Green Building Council, 2014)

- Location and Amenities (Duffy et al., 1992, Gordon-Larsen et al., 2009, World Green Building Council, 2014)

These eight factors have significant interactions and crossover between them. Daylighting has direct interaction with thermal state of an office. Windows absorb and transfer significant amount of solar radiation into indoor environment (Lyons et al., 2000). A change in thermal state may have an impact on occupant perception of indoor air quality. A decrease in temperature leads to improved occupant perception of indoor air quality (De Dear and Brager, 2002). Similarly, there is a crossover between daylighting and 'look' and outside views of an indoor environment. Occupant comfort and 'feel' of an indoor environment may get affected by the quality of outdoor views and influence the impression of an office environment (Aries et al., 2010, Laet et al., 2002). Also, the layout of an office can have an impact on its acoustic properties (Lee, 2010, Kim and de Dear, 2013). The study acknowledges the crossover and interactions amongst these IEQ factors. However, the study divides them into eight categories to collate the evidence of their individual impact on occupant productivity to underline their relevance in indoor environment design of an office. This review can be taken as starting point to develop experiments to look at magnitude and consequences of various interactions between these indoor environment qualities.

Although literature discussed above factors focuses on indoor environment quality, there is a lack of focus on occupant productivity. In light of the impact, above factors should be reviewed or their impact on occupant productivity. The next section presents a state of the art literature review in the above eight IEQ factors. 


\subsection{Physical Environment Factors affecting Indoor Environment Quality}

\subsection{Indoor Air Quality and Ventilation}

Indoor air quality (IAQ) is the degree of quality of the indoor air of a building. IAQ has a high impact on office productivity. A workplace with good air quality has higher work performance in office tasks such as text typing, proof-reading and mathematical tasks (Wargocki, 2000, Langer and Bekö, 2013, Ng et al., 2012, Fanger, 2000). IAQ studies on existing buildings following industry air quality standards have found many participants within existing buildings to have a substantial dissatisfaction rate with IAQ . They highlight various health related issues reported by some of the building occupants (Fisk et al., 1993, Mendell, 1993, Bluyssen et al., 1996). These issues include SBS (Sick Building Syndrome) symptoms, allergies and asthma symptoms (Fisk and Rosenfeld, 1997). SBS is a building related illness. The most common SBS symptoms are dry, itchy, sore and burning eyes alongside an irritated nose and sinusitis symptoms. Other symptoms include respiratory irritation, headaches, lethargy and mental fatigue (Hodgson, 2000, World Health, 1982). Global observation of these symptoms and illnesses has led to research efforts towards understanding indoor air quality and its components.

Indoor air quality is a complex entity to measure. Various time-dependent physical and chemical parameters (such as relative humidity, temperature, level of air contaminants) are constituents of IAQ. These parameters are affected by outdoor conditions (climate), building conditions (material, structure and construction), buildings' HVAC systems (Heating, Ventilation and Air-conditioning systems), the indoor space arrangements (furnishing, furniture, equipment) as well as occupants' productivity patterns. These factors are highly interdependent and are dynamically affected by multiple variations and interactions (Szczurek et al., 2015). Indoor air quality can be managed either by increasing the ventilation rate or by reducing the air pollutant load in the air. Ventilation is used to exchange the indoor air and remove carbon dioxide and other contaminants in the air (Kosonen and Tan, 2004, Seppänen et al., 1999). The ventilation rate is an efficient monitor of IAQ in a building. Higher ventilation rates result in good indoor air quality. Lower indoor air quality is associated with Sick Building Syndrome (SBS) symptoms and reduced productivity (Ezzeldin and Rees, 2013, Wargocki et al., 2000, Kosonen and Tan, 2004, Seppänen et al., 1999). Research on european countries highlight that ventilation rates below $10 \mathrm{Ls}^{-1}$ (litre per second) are associated with higher risk and prevalence of Sick-Building Syndrome and other health risks (Dimitroulopoulou and Bartzis, 2013, Seppänen et al., 1999, Fisk et al., 2009). There is a debate in the built environment sector that higher ventilation rates result in higher energy consumption. Researchers argue that higher occupant productivity by better IAQ would lead to an overall benefit for both the occupants and the building. Higher ventilation rates in a building could result in a financial return from ten to sixty times greater than annual energy and maintenance costs (Kosonen and Tan, 2004, Wargocki et al., 2003, Wargocki et al., 2000). A research study on the quantitative benefits of an increased air ventilation rate in offices across the U.S. supports the argument. The study reports the yearly economic benefit of US $\$ 13$ billion by increasing minimum ventilation rates from 8 to $10 \mathrm{l} / \mathrm{s}$ per person and US $\$ 38$ billion by increasing ventilation rates from 8 to $15 \mathrm{l} / \mathrm{s}$ per person on a U.S wide scale (Fisk et al., 2012). These benefits reflect an appreciation of better occupant performance and productivity due to better air quality.

There are different ventilation systems available to control the ventilation rate of buildings. These mainly include naturally ventilated systems, hybrid/mix mode systems and mechanically ventilated systems. Some studies indicate that mixed mode HVAC systems have higher air quality satisfaction and energy savings than other HVAC systems (Ezzeldin and Rees, 2013, Gou et al., 2014). Literature also suggests that relative to natural ventilation, air conditioning, with or without humidification had significantly higher association 
with one or more SBS symptoms (30 - 200\%) (Seppänen and Fisk, 2002). However, a ventilation system should be chosen based on various local climate factors, building type and occupant behaviour pattern and expectations (Kim and de Dear, 2012). Mechanical ventilation system is extensively used in buildings in hot climate. However, Personalised Ventilation (PV) system can be highly effective for offices in hot and humid locations such as Singapore. PV system used as a secondary system in conjunction with primary air conditioning system can reduce overall energy consumption by $15-30 \%$. It supplies fresh air directly to occupant's breathing zone. The combined effect of PV and main air-conditioning helps to enhance IAQ acceptability by the occupants (Sekhar et al., 2005). A decrease in work performance can relate to an increase in pollutant load in indoor air quality. Formaldehyde and Volatile Organic Compounds(VOCs) are the main pollutants in indoor environment (Kim et al., 2001). Chemical and Microbiological Volatile Organic Compounds (VOCs/MVOCs) in the air have a direct impact on indoor air quality (Wolkoff, 2013a). VOCs can be man-made or of natural origin. Natural origins of VOCs are oceans, volcanos and forests. Human activities in industry, petro chemistry and vehicular emissions are one of many reasons for VOC emissions (Panagiotaras et al., 2014). Apart from indoor human activities like smoking and cooking (fume), indoor elements of a building such as carpet, furniture (wood preservatives), paint products, and cleansers are also responsible for VOCs emissions (Panagiotaras et al., 2014, Chao and Chan, 2001, Berenjian et al., 2012, Association, 2011, Guenther et al., 1995). New buildings have higher VOCs levels than old buildings. Studies suggest that over a period of time, majority of buildings exhibit decreasing tendencies of VOCs in indoor environment (Shin and Jo, 2013, Langer and Bekö, 2013). The majority of VOCs exhibit irritant and odorant properties (Wolkoff, 2013b, Jones, 1999, Panagiotaras et al., 2013). There are industry standards and guidelines recommending acceptable levels of contaminants (World Health Organization, 2005, ASHRAE Standard, 1989). However, VOCs exhibit a broad diversity in their physio-chemical properties. This makes it difficult to develop standard measures for VOCs for sampling and analysis. Sampling methods depend on compounds of interest and, in particular, on specificities and sensitivities relating to human physiology (Panagiotaras et al., 2013, Teichman et al., 2015). This subjective reaction to diverse compounds makes observing and mapping VOCs in a particular environment quite complex task. The most commonly used methods for indoor air sampling and analyses are TO (Toxic Organic)methods (U.S. - EPA Compendium of Methods for the Determination of Toxic Organic Compounds in Ambient Air) and IP methods (Compendium of Methods for the Determination of Air Pollutants in Indoor Air) (US-EPA, 1999, Riggin, 1984, Panagiotaras et al., 2014, US-EPA, 1990).Fanger (1988) introduced Olf and Decipol units to measure indoor contaminants and their sources (such as buildingfurnishing material and ventilation systems). Olf is the emission rate of air pollution. It is equivalent to the emission rate of the air pollutant from one standard person. Building materials' emissions have been estimated at $0.1-0.2 \mathrm{olf} / \mathrm{m}^{2}$. Decipol is used to represent the level of perceived air quality. One Decipol represents pollution by one person ventilated by $10 \mathrm{l} / \mathrm{s}$ of fresh air. Fanger (1988) also introduced an equation to measure the number of the dissatisfied occupants as a function of the perceived air pollution using Decipol units (Kosonen and Tan, 2004, Fanger, 1988).

Above review of indoor air quality summarises four strands of research focus. These are air quality (constituents and pollutants), ventilation rate, the effect on human health, and occupant's perception and productivity. All of these aspects are interrelated and affect indoor air quality. Indoor air quality parameters and metrics are discussed in section 7.1.

\subsection{Thermal Comfort}

Thermal comfort is described as a "state of mind which expresses satisfaction with the thermal environment" (ASHRAE, 2004). It is a subjective state which varies from person to person. The judgement of comfort is a cognitive process involving inputs influenced by physical, physiological and psychological factors (Lin and Deng, 2008). Comfort is dependent on highly independent and dynamic factors such as clothing, altering activity, 
changing posture, window location and mood (ASHRAE, 2005). Achieving overall thermal comfort in a building is a complex task, as thermal comfort is an outcome of different physical parameters, creating a thermal state and understanding a collection of subjective human responses to that thermal state. Thermal comfort varies individually and geographically due to a broad range of factors such as age, sex, metabolism rate, time of the year, among many others (Cena and de Dear, 2001, Quang et al., 2014). Thermal comfort in an office is measured by analysing the number of discomfort complaints. Complaints analysis is a reactive method. By pursuing this research on IEQ, we can proactively design buildings that are more comfortable for occupants and lead to higher productivity.

Literature uses thermal sensation, thermal acceptability and thermal preference to describe the human response to thermal comfort (Langevin et al., 2013). Thermal comfort is a subjective condition for humans, but thermal sensation is an objective condition (Hensen, 1991). Thermal sensation is defined as the direction and magnitude of one's sensory perception of the surrounding thermal environment (ASHRAE, 2010). The American Society of Heating, Refrigeration and Air-conditioning Engineers (ASHRAE) define it on a seven point scale from -3 (cold) to +3 (warm). Thermal comfort is influenced by six factors. These factors are air temperature, air velocity, relative humidity, mean radiant temperature, clothing insulation and metabolic rate (Macpherson, 1962, Macpherson, 1973, Goldman, 1999, Berglund, 1977, Lin and Deng, 2008). Thermal acceptability is the degree of an occupant's approval of the environment. Thermal preference is the ideal thermal state in terms of the environment (Langevin et al., 2013). Occupant productivity increases when an environment moves from acceptable thermal state to preferred thermal state. However, preferred thermal state of an environment varies from person to person. Studies suggest that subjects with different age, gender and BMI (Body Mass Index) have different preferred thermal state (Tuomaala et al., 2013, Indraganti et al., 2015). Literature also indicate that females express more dissatisfaction than males in a thermal environment and are more sensitive to deviations from an optimal thermal environment and are less satisfied than males especially in cooler conditions (Karjalainen, 2012, Kim et al., 2013, Karjalainen, 2007).

Achieving thermal comfort in a building requires energy consumption by the heating and ventilation systems in a building (Kwok and Rajkovich, 2010). It has attracted many researchers focusing on sustainability in the built environment. Research on thermal comfort has been active for decades. The first instrumental work was by Fanger (Fanger, 1970, Fanger, 1984). Fanger (1970) developed an analytical model to predict thermal comfort. It combines four physical parameters (air temperature, mean radiant temperature, air velocity and relative humidity) with human variables (clothing insulation and activity level) to define the PMV (Predicted Mean Vote) index. The Predicted Percentage of Dissatisfied Occupants (PPD) is calculated from the PMV index (Fanger, 1984). It predicts the percentage of people who could be dissatisfied with a thermal environment. It predicts if a large group of individuals are likely to feel 'too warm' or 'too cold', defined by voting $+3,+2,-3,-2$ on the scale (Olesen and Parsons, 2002). This method uses climate chamber data and is based on the heat balance theory along with thermoregulation physiology (Charles, 2003, Djongyang et al., 2010). An alternate approach known as the "adaptive approach" to thermal comfort was proposed by De Dear (De Dear et al., 1997, Brager and de Dear, 1998). It is based on field studies and analyses human acceptability of a thermal environment. It states that the thermal acceptability of occupants influences their thermal comfort. Thermal acceptability is dependent on adaptive behaviour, physiological adaption and psychological adaption.

There are different thermal comfort standards and evaluation methods based on thermal comfort research (Olesen and Parsons, 2002, ASHRAE Standard, 1992, De Dear and Brager, 2002, ASHRAE, 2005, ISO, 2005). These standards are used by industry professionals across the globe. These standards are developed for models and studies based primarily in North America and Northern Europe (Ogbonna and Harris, 2008). They 
are appropriate for static and uniform thermal conditions and do not consider human factors like age, gender and regional behavioural actions and expectations (Zhai et al., 2015, Han et al., 2007). These standards may not be entirely accurate for different regional climates and all type of indoor activities. The standards and thermal comfort prediction methods based on 'rational approach' that do not consider age, gender and race and suggest a narrow, welldefined thermal comfort range have been challenged and proven wrong by many research studies in different parts of the world (Ogbonna and Harris, 2008, Nicol, 2004, Humphreys, 1978). The comfortable temperature of people is closely related to the mean temperature they experience. Field studies in UK, India, Iraq and Singapore indiciate that mean comfort temperature changes with the mean temperature experienced, especially in naturally ventilated buildings (Nicol et al., 2012, Humphreys et al., 2007, Nicol and Humphreys, 2002, Humphreys, 1978, Humphreys, 1975, Nicol and Humphreys, 1973). This variance in comfortable temperature highlights the significance of understanding the contextual climatic conditions and occupants' profile of the building. Research also indicates that clothing (acceptable formal dress) also influence the occupant (employee) comfort (Morgan and de Dear, 2003). The formal dress code varies from culture to culture across the globe. This presents an opportunity to map a copmparision amongst various countries and their attire in line with acceptable comfortable temperature.

Thermal comfort plays a significant role in occupant productivity. Dissatisfaction with thermal comfort leads to productivity loss (Roelofsen, 2015, Akimoto et al., 2010a, Lan et al., 2011, Fisk, 2000b). Studies indicate that temperature change within the $18^{\circ} \mathrm{C}-30^{\circ} \mathrm{C}$ range can influence the performance of office occupants in tasks like typewriting, learning performance and reading. The temperature range $21^{\circ} \mathrm{C}-25^{\circ} \mathrm{C}$ is a stable temperature range for office productivity. There is a decrease in occupant performance by $2 \%$ per $1^{\circ} \mathrm{C}$ increase in temperature in the range of $25^{\circ} \mathrm{C}-30^{\circ} \mathrm{C}$ (Seppanen et al., 2003, Seppänen and Fisk, 2006). Ambient temperature plays a significant role in defining the thermal comfort of occupants, but local thermal conditioning or task conditioning also influence occupants' comfort levels. Task conditioning systems aim to maintain thermal conditions for a localised zone, and they are controlled individually or by a group of occupants (Zheng et al., 2009a, Bauman and Arens, 1996). They are utilised based on evidence that indicates that personal control over thermal conditioning systems helps to improve productivity (Bauman et al., 1998, Akimoto et al., 2010b, Seppänen and Fisk, 2006). Local thermal conditioning and personal control is highly applicable in office with employee groups seated in different zones. It is also applicable in office that involve employees to work in various task demanding different levels of physical activites. While, thermal control amongst employee is associated with higher comfort and satisfaction, it also raises certain problem related to the control behaviour of the occupants. Acceptance of a thermal enviornment is subjective and directly related to the expectation of the occupant. There are individual differences in user's comfort expectation and expectation from the enviornment (Moezzi, 2009). This could result in energy wastage due to inefficent use of thermal control system (Shahzad et al., 2016). Energy wastage due to inefficent control of thermal control system in offices is related to lack of knowledge of system operation and general thermal comfort disagreement amongst occupants. Providing energy awareness can cause behavioural change towards more energy concious operations and may result in energy saving along with occupant comfort and productivity (Tetlow et al., 2012, Nisiforou et al., 2012). Innovative building energy and comfort control strategies must be developed and implemented to adjust occupant behaviour and devices' control. A real world interface with strong computational support might help in this context

Research on the relationship between office tasks, temperature and productivity indicates that different functions have different optimum temperatures of productivity (Huizenga et al., 2006, Tanabe et al., 2007). Optimal thermal comfort and optimum performance may not coincide with the particular type of tasks. For example, creative mental work may have the optimal thermal temperature and optimum performance coinciding. However, another kind of mental work may require a slightly cold temperature for optimum/increased productivity 
(Fisk, 2000b). These findings highlight the importance of focusing on offices tasks when determining the thermal design for an office. Application of local control system in different task zones of an office would help to maintain an overall occupant comfort and productivity.

Thermal comfort measurement parameters and metrics are discussed in section 7.2.

\subsection{Lighting and Daylighting}

Daylight influences our day-to-day tasks throughout the year. Daylight controls our biological clock/internal clock which has been set for millions of years according to the rising of the sun and the darkness of night. This biological clock has been passed on by our ancestors. We need light as it is a regulator of our physiology and performance (Aries, 2005). Office employees spend most of their time indoors thus office tasks are dependent on indoor lighting or any available daylighting. Daylight is considered to be the best source of light with excellent colour rendering that offers the best light for human visual comfort. It provides a sense of cheeriness and brightness and has a positive impact on people (Li and Lam, 2001, $\mathrm{Li}, 2010)$.

Buildings worldwide contribute to roughly $40 \%$ of the world's annual energy consumption (Omer, 2008). Lighting has the highest share (33\%) in the calculation of average electricity consumption in the UK office buildings (CIBSE, 2015). In the USA, commercial buildings account for one-third of the nation's primary energy consumption. Artificial lighting utilises $25-40 \%$ of the total commercial buildings' energy consumption (Krarti et al., 2005). In Spain, lighting contributes to $33 \%$ of total energy consumption in offices (Pérez-Lombard et al., 2008). This highlights the occupants' dependence on artificial lighting in an office. It also indicates that artificial lighting is a major contributor to carbon dioxide emissions and global warming as it utilises one-third of the electricity bill (Busch et al., 1993). Efficient daylighting measures and intelligent lighting systems can help reduce the artificial energy load and thus the carbon footprint of a building.

Organisations that pay attention to the importance of daylighting achieve higher occupant productivity in their workplaces (Yang and Nam, 2010, Fay et al., 2002, Ander, 2003). Companies like Lockheed Martin and VeriFone have reported a $15 \%$ decrease in absenteeism and a $47 \%$ increase in attendance, respectively, in buildings designed to provide maximum daylight for their occupants (Romm and Browning, 1994).

Building occupants prefer natural light/sunlight over artificial light (Boyce et al., 2003, Elzeyadi, 2011, Galasiu and Veitch, 2006, Leslie, 2003, Guzowski, 2000, Reinhart, 2002). Occupant preference is due to physical, physiological and psychological reasons. Physically, there is not much difference as artificial lamps can cover the spectrum and colour rendering of daylight at a certain cost. However, the literature highlights that physiological and psychological reasons affect the visual and circadian system in humans (Rea et al., 2002). Human visual system parameters such as visual size, luminance contrast, colour difference, retinal image quality and retinal illumination jointly affect the work performance of any task (Boyce, 1997). Natural light's levels are above the order of magnitude of normal electric lighting levels. They influence melatonin, a hormone responsible for regulating the body's internal clock and these light levels (Rea et al., 2002, Van Bommel and Van den Beld, 2004). It relates to the finding that natural light is believed to increase alertness for monotonous work during office hours (Boyce, 1997, Nagy et al., 1995). These studies demonstrate the importance of natural light for the human body to work efficiently in daily activities.

A study of office workers focusing on the importance of windows and their benefits reports that almost $99 \%$ believed that offices should have windows and that $86 \%$ considered daylighting to be the preferred source of light for office tasks (Cuttle, 1983). Windows also provide views with different visual information like weather, nature and surrounding activities. These views could be aesthetically pleasing and could have a positive impact on the 
occupants' productivity (Heerwagen and Orians, 1984, Heerwagen and Heerwagen, 1986). The literature confirms occupants' liking of windows. However, the acceptability of window size varies depending on factors such as the amount of indoor and outdoor light levels, sun position and sky luminance (Ne'Eman, 1970).

Studies focusing on window sizes and glazing highlight a broad spectrum of window size preferences among occupants and it is not necessarily the case that all the occupants universally prefer a large window size. A study reports that only $43 \%$ of respondents prefer large windows for an office environment, and different types of spaces have different illumination requirements (Butler and Biner, 1989). A case study focusing on high-rise office buildings reports that only $56 \%$ of the respondents believed in the importance of window access. The size of the window was unimportant to $86 \%$ of the workers as long as the light levels were satisfactory (Wotton, 1982). The orientation of the window produces distinctly different control responses due to solar radiation and wind direction (Zhang and Barrett, 2012b). A glazed building's southern side uses more blinds than on the northern side, indicating the occupants' disliking of an excess of direct sunlight (Rubin et al., 1978). Solar altitude and solar radiation plays a huge part in blind usage in windows, indicating annoyance created by excessive sunlight (Zhang and Barrett, 2012a). Window control is highly correlated with outside air temperature, the season of year, time of a day and the occupancy pattern of the office (Zhang and Barrett, 2012b). Geographical location, local climate and immediate surrounding plays and important role in defining the size, position of the window or type of glass façade. If efficiently designed, glass façade is applicable in Hong kong's sub-tropical climate and closely packed buildings to harvest adequate sunlight (Li and Tsang, 2008). However, the inadequate design and misuse use of glass façade in high towers of Dubai without considering orientation and solar attitude leads to occupant annoyance and use of blinds (Aboulnaga, 2006). The use of blinds leads to use of artificial lighting and wasting available sunlight and increase in $\mathrm{CO}_{2}$ emissions. External design features in façade can be used to avoid glare problem even in the hot and high solar radiation areas (Lim et al., 2012). Traditional dwellings in India use 'jaali' (latticework on stone or wood) in windows in tropical monsoon, arid (steppe) and arid (desert) climate areas as passive design strategy to maintain ventilation and temperature along with adequate daylight without any glare (Srivastav and Jones, 2009). Similarly, designers use double façade to reduce heat gains and glare problems from direct sunlight in hot climatic. The use of traditional mashrabiya' screen as second skin in Masdar city project in Abu Dhabi and screen pattern on Doha tower in Abu Dhabi are great examples of reducing heat gains and glare problem from direct sunlight in hot climate (Boake et al., 2014). The daylight design of a building should be designed according to local climate, building's orientation, solar altitude, and immediate surroundings, nature of the space, and layout of the building alongside and daylighting availability. The above research indicates how people in different geographical regions have developed native architectural practices for lighting.

A daylighting design can be any method by which natural light is brought into a room to provide adequate lighting conditions. It involves analyses of daylight availability which is dependent on the light available from the sun and the sky at a certain locations, times and weather conditions (Guzowski, 2000). Daylight analysis lays the path to the daylighting strategies of side-lighting (windows) and top-lighting (skylights, roof monitors) (Manning, 2006). Illuminance from natural sources is determined by the Daylight Factor (DF). The Daylight Factor is the percentage of outdoor light under overcast skies available indoors. It takes three components into account; the sky component (SC), the light from external surfaces/externally reflected component (ERC) and the light reflected from surfaces within the room/internally reflected component (IRC) (Fontoynont, 2014, Reinhart et al., 2006, Hopkinson, 1963). 
The recommended level of Daylight Factor (DF) for different offices depends on the type of office task. Simple tasks like reading, filling only require $1.5-2.5 \%$ daylight factor while draughting and fine machine work requires up to $8 \%$ daylight factor (Stein et al., 1992).

Excess of direct sunlight and artificial light can result in a glare that results in visual discomfort. A low level of lighting can lead to ocular discomfort and improper lighting design leads to worker dissatisfaction. Glare-free and thermally comfortable spaces have a high effect on occupant productivity (Selkowitz, 1999, Abdou, 1997, Hemphälä and Eklund, 2012). The Illuminating Engineering Society of North America (ILESNA) describes the density of luminous flux on a surface, which is represents flux per unit area of distribution. (Rea, 2000). A high level of illuminance from daylight may cause glare inside a building, called Daylight Glare (Rea, 2000). Daylight glare has the measurement metric known as Daylight Glare Index (DGl). Office areas are recommended to have $22 \mathrm{DGl}$ for good visual comfort (Cantin and Dubois, 2011, Hopkinson et al., 1966). Glare can be caused by combination of daylight and artificial lighting. Lighting control mechanisms can be used to control it.There are two types of smart daylighting control to reduce a building's energy consumption (Doulos et al., 2005, Chang and Mahdavi, 2002, Sullivan et al., 1994). These are:

- Continuous dimming - This strategy uses a sensor that reads the exterior illuminance and controls the artificial lights inside a building to maintain a set indoor illuminance level. This technique is highly dependent on the location and hardware quality of the sensor. This is strategy also uses automated shading devices in responsive façade design to efficiently manage the overall illuminance levels of the indoor space. Al Bahar towers in Abu Dhabi are great example of managing high level of direct sun using responsive façade structures to manage solar gains and excessive daylight (Boake et al., 2014). This strategy would be also successful in climatic areas with high level cloud movements that change outdoor lighting levels.

- Switching control - Switching loads on and off manually or with relays controlled by occupancy sensors. It is a more rudimentary strategy and becomes less efficient when daylight levels fluctuate more rapidly.

Lighting and Daylighting measurement parameters and metrics are further discussed in section 7.3.

\subsection{Noise and Acoustics}

The hearing ability is one of the five human senses. Varieties of sound regularly reach our ears and get transmitted to our brain. The World Health Organisation (WHO) describes any unwanted sound as noise. The effects of noise in terms of an auditory response can be described in psychological attributes such as annoyance, noisiness and loudness (Berglund et al., 1996, Stansfeld and Matheson, 2003, Ayr et al., 2003). Magnitude can characterise sound (or noise). It is measured on a log scale of decibels (dB), sound power and sound pressure levels (SWL and SPL).

Noise and acoustics have high relevance in building design. A building's acoustic performance becomes more important in office design as most office tasks require a degree of noise control to enable the occupants to work efficiently. Bad acoustic and noise performance can lead to dissatisfaction with the office environment and can affect workers' performance (Frontczak et al., 2012, Balazova et al., 2008, Toftum et al., 2012). Noise in an office can have two locations for sources; external or internal. External sounds include traffic, the public, air traffic, machinery. Internal noises include co-worker conversations, one-minute requests, machine sounds such as telephones and other office equipments (Banbury and Berry, 2005, Ayr et al., 2003). The neutral sound pressure of a typical air-conditioned office is between $45 \mathrm{~dB}$ and $70 \mathrm{~dB}$ (Mui and Wong, 2006). Occupant discomfort is an outcome of 
different Indoor Environment Qualities (IEQ). Acoustic sensation and thermal sensation have an equivalent effect on an employee. A temperature change of $1^{\circ} \mathrm{C}$ has the same effect on productivity as a change in noise of $2.6 \mathrm{~dB}$ (Pellerin and Candas, 2004). Continuous and prolonged noise at higher levels can induce and increase stress levels over time. Studies suggest that occupants subjected to continuous transport/traffic noise showed higher levels of blood pressure and stress hormones (Evans et al., 1998). Internal machinery such as fax machines, telephones and air conditioning systems can also produce annoyance that may result in similar stress levels (Ayr et al., 2003). Office-related tasks are highly affected by speech and office noise. In a study, researchers experienced a drop in performance by 66 percent in 'memory for prose' tasks when participants were exposed to different types of background noises. About 99 percent of the people surveyed in an experiment reported on their concentration being impaired by office sounds such as unanswered phones and background speech (Banbury and Berry, 2005). Both internal noise and external noise affect occupant's performance and leads to stress and anxiety and possibly creating long term health issues for occupants.

External building elements and design can protect the office interior from external noise. Internal arrangement and office layout influence the internal noise in the office environment. Open plan office noise can have a negative impact on the fatigue, motivation and performance of employees (Jahncke and Halin, 2012). Tasks associated with word processing and numbers' calculation are affected by internal office noise. Open plan office employees are more prone to privacy issues and disturbances due to the various office sounds around them (Toftum et al., 2012, Balazova et al., 2008). Acoustic discomfort can be reduced by maintaining low level background noise in an office environment. This helps to reduce the distraction from acoustical spikes created by unwanted loud noise. Open plan offices have a minimum background noise level (LAeq,t) of $45 \mathrm{~dB}$. Private/cellular offices have 40dB noise level recommendations as per BS8233 - 2014 (British Standards Institution) (Field, 2008, Field and Digerness, 2008). Office designers use a technique called sound masking. It uses a sound generator linked to public announcement speakers. It produces white noise to maintain the primary sound levels in an office (World Green Building Council, 2014).

Acoustic comfort can also be achieved using sound absorbing materials in the room. Acoustic quality of a room is described by the reverberation time and the sound absorption of a room. It is related to the absorption characteristics of the room surfaces and the volume of space (Payne, 2013). Privacy may be a concern in a cubicle/cellular based office arrangement. Hence, good insulation and moderate background noise may be required to mask the speech in cubicles. Architects can use office layout, materials selection of internal partitions and external envelope to reduce acoustic discomfort of an office environment.

Noise and Acoustics measurement parameters and metrics are discussed in section 7.4.

\subsection{Office Layout}

Office layout design is one of the leading indoor qualities that influence workplace performance and behaviour. Design, proximity and privacy influence our work pattern and performance (Haynes, 2008b, Lee, 2010). The physical environment of the workplace influences the recruitment, retention and productivity of the organisation, thus affecting an organisation's business capability to achieve success (Wheeler and Almeida, 2006). The office layout of an organisation should be well designed to ensure efficient work process to enable organisational success. The literature reviewed iterates the debate and discussion on office layouts and their effect on occupant productivity. It highlighted two key themes: the issue of an open office versus cellular offices and their relationship to the office work processes (Stallworth Jr and Kleiner, 1996, Haynes, 2008b). 
Many pieces of research highlight that a mismatch of the office environment and an organisation's work process leads to productivity loss (Mawson, 2002, Laing et al., 1998). To understand work patterns more efficiently, Liang proposed four metaphors for office environments that reflect the work processes of an organisation. These are Hive, Cell, Den and Club. Liang emphasised the importance of understanding the office work structure when designing an office layout (Laing et al., 1998).

- Hive: This is a combination of cellular or combi offices which includes both cellular and open plan. This is ideal for organisations that have individual routine work which requires low interaction and high individual work. These are the organisations where majority of the work can be done at a simple workstation during regular working hours.

- Cell: The use of cellular offices is generally suitable for organisations which have a high level of concentrated individual work with barely any interaction requirement. Individuals occupy the office at irregular time patterns based on requirements.

- Den: This type of layout is suitable for organisations which require high level of group working with a low level of individual work.

- Club: This type of layout includes combi offices along with hot desking facilities. This is suitable for organisation which is involved in knowledge work. It is interactive and autonomous in operation. Occupancy pattern is intermittent and extends over usual hours.

These office environment models represent a variety of work processes in an office and how an office environment can accommodate different processes by providing different layouts.

The suitability of an office layout is also affected by the complexity of employees' tasks. Task complexities have shown to affect employee performance and reaction to workspace (Maher and von Hippel, 2005, Stone, 2001). An Office layout that compliments work process of an organisation can help the workflow to efficiently stream through the office reducing time and improving productivity.

Office layout is a physical environment that influences the behaviour of the office occupants. Haynes (2007a) provides evidence supporting the fact that distraction is the component that has the most negative impact on perceived productivity and interaction has the most positive effect on perceived productivity. Office workers in most organisations wish to have distraction-free solo work and opportunities to have informal interaction with colleagues (Haynes, 2007b, Roper and Juneja, 2008, McCoy, 2002, Heerwagen et al., 2004, Chachere et al., 2003). The physical setting and layout of the workspace is part of organisational culture. Literature indicates that physical setting and artefacts play a crucial role in defining and changing organisation's culture(Hatch, 1993, Kallio et al., 2015, Lindahl, 2004, Lamproulis, 2007, Barclay and York, 2001). The design of physical environment plays an implicit yet significant role in developing a culture that promotes organisational creativity and knowledge sharing. It affects equality, openness and collectivity of an organisation's culture(Kallio et al., 2015). However, national culture also plays significant role organisation's culture and office layout. A study highlights that Arab national culture's emphasis on trust, 'wasta' (use of personal connections), status, power reflects in the office design. Lack of openness, equality of space and informal gathering area are the direct implication of Arab culture's high collectivism (Al-Esia and Skok, 2015). This reflects that office design and layout is highly affected by external factors, and it will be influenced by organisational and national cultures. The literature suggests that occupants feel more distracted in an open plan office as compared to a cellular office (Brennan et al., 2002). Distraction frequency was found to be the highest in an open-plan office (65\%) followed by double-room occupancy $(53 \%)$ and was least from single-room occupants (29\%) (Brill and Weidemann, 2001). The open plan office also reports satisfaction inversely related to proximity to a window. 
Employees experience a lack of visual and acoustic privacy and feel satisfied with high partition and a window. It is also noted that female exhibit higher dissatisfaction than male counterparts (Yildirim et al., 2007). The level of dissatisfaction due noise and lack of privacy goes higher with the size of the open-plan offices. Studies indicate cellular office and flexoffice have lower dissatisfaction than open-plan offices office (Danielsson and Bodin, 2009). Cellular offices allow less distraction than open-plan offices but they do not promote informal interactions and quick access to colleagues. The open-plan office has been used mainly to reduce accommodation costs, but higher density in open-plan offices also leads to a higher load regarding lighting and ventilation. This strategy affects overall environmental satisfaction and productivity (Veitch et al., 2002).While open plan offices have shortcomings, cellular offices may or may not serve the work processes of most organisations. Van der Voort emphasises the importance of shared areas whilst limiting the amount of dedicated fixed workplaces (Van der Voordt, 2004). He recommends creating innovative workplaces/combi-offices that allow occupants to transfer information and concentrate on work, yet have shared interaction zones. Combi offices have a mix of shared and private workspaces that allow the occupants to overcome the disadvantages of both cellular offices and open plan offices.

Office Layout measurement analysis and metrics are discussed in section 7.5.

\subsection{Biophilia and Views}

According to Wilson (1984), Biophilia describes the link between nature and humans. Humans have an innate tendency towards any living form. We are highly responsive to nature's forms, processes and patterns (Nabhan et al., 1993). These psychological mechanisms originate from the prehistoric era when human interactions with other living species (plants and organisms) were more direct, active and frequent than in the current urban living setting (Krčmářová, 2009, Heerwagen, 2009). A study has provided evidence that humans have a higher level of happiness and well-being in the natural environment (MacKerron and Mourato, 2013). We have made significant transformations to our living habits and surroundings since prehistoric times. Our current living conditions in cities allow fewer interactions with other species. It has led to a decrement in human well-being and happiness.

Bringing natural environment or greenery inside an office has a positive effect on the occupants' satisfaction (Kellert et al., 2011, Gray and Birrell, 2014, Heerwagen and Hase, 2001). Greenery in offices relates positively to productivity and negatively with stress in occupants. Indoor plants help to improve indoor air quality (Lohr et al., 1996). They assist in reducing indoor air pollution by reducing the volatile organic compounds produced by different indoor furniture and synthetic materials (Grinde and Patil, 2009). Passive viewing of natural stimuli through windows can reduce stress and elevate the positive mood of occupants (Heerwagen, 2003). A field study reports that workers with a window view of nature felt less frustrated and more content as compared to workers with a view consisting only of the built environment (Kaplan and Kaplan, 1989). Plants and nature help in reducing stress and anxiety even when outside the building. Views of nature and plants from windows have been reported to help in reducing the anxiety and tension of occupants and to assist in increasing occupant productivity and well-being (Chang and Chen, 2005). A study by American psychologists includes windows with outside world views as one of the primary requirements for office occupants to achieve satisfaction in an office space (Kellert et al., 2008).

The introduction of low-cost Biophilia can have healthy effects on occupants and produce higher returns. Children can learn up to $20 \%$ faster under daylight environments (Romm and Browning, 1994). Health benefits and happier psychological support affects workers' perception towards the workplace. A study reports a reduction of $10 \%$ in workers' absenteeism due to the introduction of Biophilia in office space (Elzeyadi, 2011). Heerwagen 
highlighted eight dimensions of biophilic designs. These design dimensions are the prospect of views, refuge, water, biodiversity, sensory variability, biomimicry, playfulness in design, and enticement (Heerwagen and Hase, 2001). Biophilia-based design has three concepts: Nature in space, Nature analogues, and Nature of space (Bright, 2012):

1. Nature in space indicates a fusion of greenery in the office layout. It can include potted plants, water features, and gardens. It also includes courtyards with or without gardens. Apart from thermal and ventilation benefits, courtyards have been preferred due to their sense of openness and closeness to nature. Presence of courtyard is strongly evident in traditional architecture of countries such as India, Iran, Rome, Mexico, China, Jordan and Morocco (Asher, 1992, Soflaee and Shokouhian, 2005, Muhaisen and Gadi, 2006, Lopez, 2010, Keswick et al., 2003, Daher, 1999, Ragette, 2003, Edwards, 2006).

2. Nature analogues include artworks, biomorphic forms and the use of natural materials to arouse the feeling of life. The most common analogues are nature's paintings. Using painting of different types of landscape such as mountains, water bodies, rivers, lakes, sea helps to arouse the feeling of life in an indoor environment.

3. Nature of space refers to the psychological and physiological human reaction towards spatial configuration. It indicates that humans prefer areas with moderate depth and openness due to the evolution of mankind which primarily happened in the areas of lowgrowing grasses, a cluster of trees and broad vistas (Bright, 2012, Kellert et al., 2011).

Introduction of Biophilia and availability of views should be part of basic design principles of a workplace design. The main aim of a design is to provide best functional and conducive design for the occupants and including Biophilic design features promotes occupant wellbeing and productivity.

Biophilia and views' parameters and metrics are discussed in section 7.6.

\section{$\underline{5.7 \text { Look and Feel }}$}

The look and feel of an office environment can have an impact on our sense of well-being. Good aesthetics act as a pleasing feature in any environment. Shapes, textures and the colours of the immediate environment affect office occupants. Studies indicate that human psychological responses vary due to different colours (Mahnke, 1996). Colour schemes and the aesthetics of an indoor environment affect human performance and productivity (Kwallek et al., 1988, Öztürk et al., 2012). Humans have ingrained reactions to different colours due to our relationship with nature. For example, the colour green reminds us of an environment that gives us calm and harmonious feelings (Ou et al., 2004).

The texture of an object is as important as its colour. Textures are an important part of our memory and remain in memory like shapes and colours. It is the combined effect of colour, texture and the shapes of interior design in an office environment that leads to the overall feeling of well-being in a workplace (World Green Building Council, 2014).

An organisation's brand and value image influence its long-term business strategy. The aesthetic value of an office design is part of the organisation's image and identity amongst its clients and customers. Workplace designs are recommended to be more focused on representing the ethos of a business/organisation. This would enable an employer to have constant visual stimuli that remind employees about the ethos of the organisation. It would also help in the absorption of organisational culture among the employees (Dean et al., 1997, Vilnai-Yavetz et al., 2005).

Spatial shapes also play a significant role in defining the comfortability of a workplace. Spatial proportions explain how someone would feel in a space. A big atrium in an office can be welcoming while a small L-shaped entrance may subconsciously put an adverse effect on the occupant. Creative tasks can be easily achieved in a volumetric and open space, while 
tasks requiring concentration require more comfortable, low ceiling and smaller environments (World Green Building Council, 2014). A good office design would incorporate aesthetical features such as colour, texture, spatial shapes that compliment company's organisational values and provides a conducive space for employees' tasks and routines.

Look and feel parameters of an indoor environment and its metrics are discussed in section 7.7 .

\subsection{Location and Amenities}

The location of the office is not part of the physical envelope of a workplace. Amenities of a workplace may or may not be part of the building. However, they are highly significant in defining the quality of workplace. Thus, they have been included in the literature review.

The location of a site plays a significant role in the selection process of houses and workplaces. Offices located in the proximity of public infrastructure have higher employee satisfaction and attract more employees (Leaman, 1995, Duffy et al., 1992). Offices located near major public transport infrastructure have the potential to reduce $20-40 \%$ fuel usage per person (Haider et al., 2013).

Offices that are located near to good quality public transit services and cycle tracks and offer good walkability tend to provide easier and convenient access to its employees. A range of health and well-being benefits are associated with better transport connectivity and the location of an office. Research suggests that public transit users walk 19 minutes getting to and from public transportation and every kilometre walked reduces the risk of obesity by $5 \%$, whereas the likelihood of obesity increases by $6 \%$ with each mile spent in the car (Foundation, 2012). These health benefits help in keeping employees healthier and hence more productive in the workplace. Employees who regularly cycle to work are less frequently sick. Cyclists who are employees report less absenteeism as compared to colleagues who do not cycle (Gordon-Larsen et al., 2009).

Amenities' provision near the workplace can influence the productivity of employees. Studies suggest that such facilities sponsored by an employer may enhance an executive's trust of a company. It also helps to motivate the employees. Amenities and services have been ranked fourth in a workplace satisfaction survey (Deng and Gao, 2010). It is recommended to have four types of primary amenities near a work environment (World Green Building Council, 2014):

\section{Healthcare/ clinic}

It is very common for employees to go for a regular health check-up. Availability of healthcare facilities in the proximity of the workplace helps to reduce the time of travel between workplace and clinic. Employers have direct benefit with employees spending less time in travelling during work hours. It also has an indirect benefit that more employees would be able to go for health appointments, resulting in higher health conscious/aware employees. It would result in overall long-term benefit of less sick leaves.

\section{Recreational spaces/ sports facilities}

Various recreational spaces and parks allow employees to relax during lunch/breaks . Sports facilities also allow keeping their exercise regime, helping them to maintain better health. Green surroundings around the office also tend to improve the well-being of the occupants (as stated in Biophilia factor). Sports facilities near workplace have many benefits. Employees who want to stay fit have better accessibility to sports facilities and would spend less time travelling to the gym. Organisations with recreational and sports facilities have benefit to sponsor team-building exercises in intra and inter-company 
leagues. These recreational exercises provide better team bonding and reduced stress. These activities contribute towards improving well-being of the employees, leading to better productivity.

\section{Entertainment options}

Entertainment options offer employees the benefit of relaxation and enjoyment. Accessibility to entertainment options like theatres and cinemas increases the likelihood that employees will attend a team building events. It can be powerful in developing team strengths and addressing conflicts (World Green Building Council, 2014).

\section{Childcare facilities}

Childcare facilities near workplace provide direct benefits to both employees and employers. Employees can have peace of mind that child being cared nearby. They can reach office on time and work with a bit more flexibility with no stress about drop-off and pick-up from a childcare facility. Research indicates that childcare facility in a workplace is an attractive feature for the elite talent and it is one of the key factors in productivity. According to a report, $68 \%$ of parents indicated that they would have missed work if they had not used the onsite childcare centre, leading to significant productivity improvements (Horizons, 2004).

Above research section indicates that a convenient office location with transport accessibility and proximity to various amenities could help to improve office productivity and well-being of the employees.

Location and Amenities parameters are discussed further in section 7.8.

\subsection{Occupant Productivity Measurement and Data Collection}

This literature review study has highlighted various physical indoor factors which affect occupant productivity. Research studies in the field of the indoor environment focusing on occupant comfort and productivity have used different methods of data collection to highlight the occupants' discomfort and its relationship to productivity. The literature review suggests that questionnaires/surveys on occupant comfort and the physical measurement of indoor environment factors have been used jointly as a data collection strategy in most of the case studies. The literature highlights Post-Occupancy Evaluation (POE) as a widely used method for evaluating building performance after a building has been built and occupied (Göçer et al., 2015).

POE is used to conduct the data collection of real world data from buildings, followed by its formulation into different logical trends and deviations for relevant purposes. It has been used for the primary purposes of identifying inefficiencies in building energy consumption and in building maintenance systems and in identifying occupant comfort guidelines. POE uses three sources for data collection. These are occupant feedback through questionnaires and interviews (subjective assessment), bill and metrics (objective \& indirect assessment) and the physical measurement of the environment using laboratory devices/sensors (Ozturk et al., 2012).

POE can been used with soft landings approach. Soft landing approach helps to minimize the change in design deliverables from inception stage to operation stage. It helps to provide 'bump free' transition from design to construction and then handing over to the client. The project team oversees the building performance during first three years of the operation and monitor it against its design specifications. The team also uses survey to map occupant response to building performance to analyse occupant satisfaction (Way and Bordass, 2005, 
Way, 2006). Soft Landing approach along with POE can be effectively used for new building design and delivery. It is high application potential in Middle - east region with high level of building production. This approach can be applied to refurbishment projects to ensure occupant satisfaction and wellbeing. Europe's building stock consumes $40 \%$ of the total energy and is responsible for $36 \%$ of the total greenhouse emission. Currently, about $35 \%$ of the EU's buildings are over 50 years old. By improving the energy efficiency of buildings, we could reduce total EU energy consumption by $5 \%$ to $6 \%$ and lower $\mathrm{CO} 2$ emissions by about $5 \%$ (EC, 2013). Soft Landing approach with POE can be used to refurbish building stock, ensure better project delivery and handover ensuring higher occupant satisfaction and wellbeing.

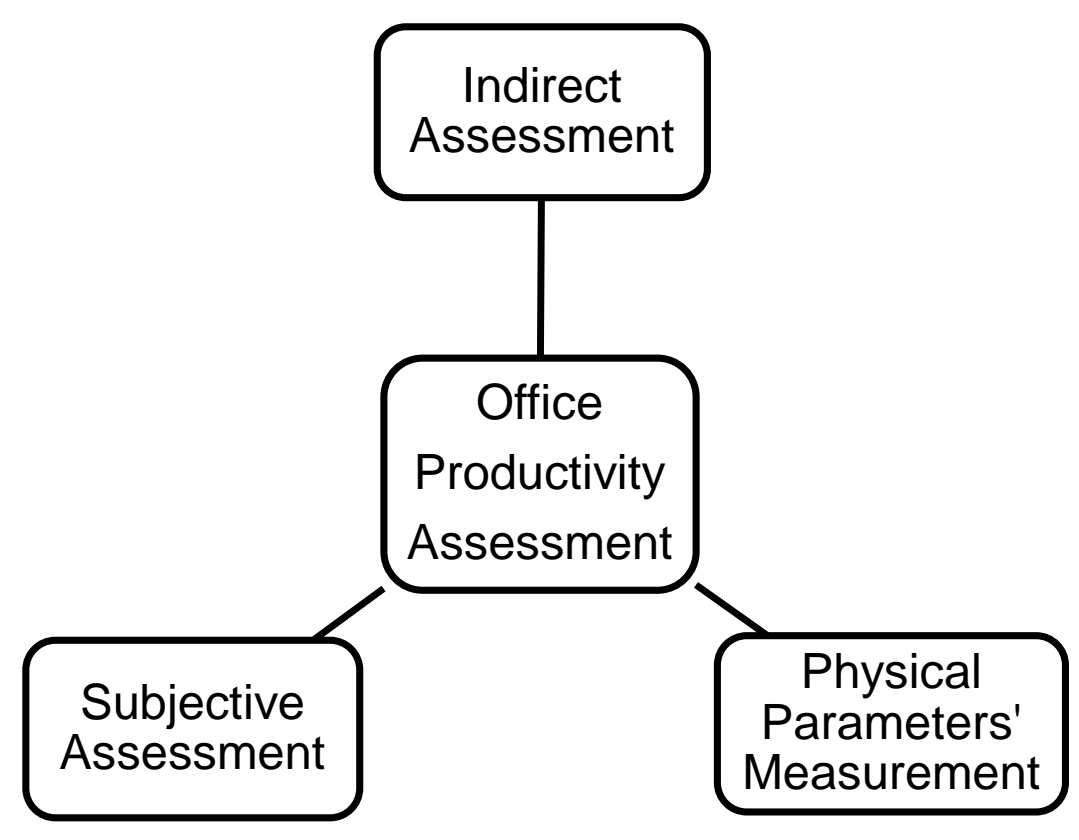

Figure 2 - Occupant Productivity Assessment

\subsection{Subjective Assessment}

Occupants' feedback on changes in the physical environment can be collected using a field survey (interviews and questionnaire). Interviews are utilised in a detailed study with a very low sample volume. A field survey is used to remotely gather information by sending a questionnaire to multiple participating occupants. A field survey can be conducted by the paper-based method or via an email request with online database/online site link.

There are various building standards and surveys that on energy consumption and occupant comfort.

Below is a list of a few survey instruments used in the industry (Dykes and Baird, 2013).

1. BOSTI (Buffalo Organization for Social and Technological Innovation) - (Brill et al., 1985)

2. BUS (Building Use Studies Occupant Survey) (Dykes and Baird, 2013, Leaman and Bordass, 2001)

3. HOPE (Health Optimization Protocol for Energy-efficient Buildings) (Bluyssen et al., 2011)

4. REF (Ratings of Environmental Features) (Stokols and Scharf, 1990)

5. CWRE (Checklist of Work Related Experiences) (Stokols and Scharf, 1990)

6. AMA WorkWare (Alexi Marmot Associates) ((AMA), 2004) 
7. DQI (Design Quality Indicator) (Prasad, 2004)

8. BASE (Building Assessment Survey and Evaluation) (Levermore et al., 1999)

9. ProKlima (Bischof and Bullinger, 1998)

10. ASHRAE RP-884 (de Dear and Brager, 1998)

11. CBE Survey (Centre for the Built Environment) (Zagreus et al., 2004)

12. OPN (Office Productivity Network) (Oseland, 2004)

All the survey instruments are applicable in offices. BUS and AMA are also applicable in residential and educational buildings. BOSTI (1977) is the first survey instrument for offices. HOPE (2002) is the latest survey instrument. All the survey use either 5 or 7 point scale in the survey questions. BOSTI, REF, CWRE, BASE, Proklima, ASHRAE RP-884, and CBE developed in the USA. BUS, AMA, DQI and OPN were developed in the UK and HOPE, Proklima were developed in Europe. BASE, Proklima, ASHRAE RP884, and CBE and HOPE use physical measurements along with survey instruments. The rest of the survey designs only use survey instruments. CBE database with 600 buildings in US, Finland, Germany, Mexico, Italy and BUS database with 400 organisations' building worldwide are the most popular survey design. Having such large databases gives the ability to benchmark building performance and identify opportunities for improvement.

\subsection{Indirect Assessment}

The literature suggests that there are different indirect methods to measure productivity in an office environment. These include measuring absenteeism in employees, the number of hours worked each week, the number of grievances filed and employee turnover (Feige et al., 2013). These methods can be used to calculate the employee productivity trends along the self-reported productivity by employees.

\subsection{Physical Parameters' Measurement}

Previously, researchers used bulky laboratory equipment (along with their connections) and apparatus for measuring the indoor physical attributes in a building. However, the technology evolution is changing data collection techniques. Buildings are becoming more intelligent and adaptive using wireless data collection devices (see Table - 2). Current technology enables a researcher to collect various physical attributes by a single device/sensor. These devices can be wirelessly connected to a monitoring device that gathers and analyses the received data.

\begin{tabular}{|c|c|}
\hline Classification of sensors & Sensors \\
\hline HVAC and Indoor Air Quality & $\begin{array}{ll}- & \text { Temperature } \\
\text { - } & \text { Humidity } \\
\text { - } & \text { Carbon oxides }\end{array}$ \\
\hline Occupancy sensors & - $\quad$ Motion sensors attached to lighting systems \\
\hline Safety and security sensors & $\begin{array}{ll}\text { - } & \text { Motion sensors for alarm systems } \\
\text { - } & \text { Fire detecting sensors } \\
\text { - } & \text { Gas detecting sensors } \\
\text { - } & \text { Smoke detectors }\end{array}$ \\
\hline Outdoor Sensors & $\begin{array}{ll}- & \text { Outdoor motion sensors for security } \\
\text { - } & \text { Compact weather stations }\end{array}$ \\
\hline
\end{tabular}

Table 2 - Various sensors used in the built environment (Ozturk et al., 2012)

Today's technology also allows remote access to the sensors. The data can also be backed up in cloud storage along with cloud computing and analysis capabilities to present the analysed result to the client. These remote sensing devices/sensors provide digital data that 
directly link with BIM (Building Information Modelling) tools to provide a visual representation of the different physical attributes of a building.

The literature highlights research studies that have achieved the synchronisation of various remote sensing devices with BIM and a Geographic Information System (GIS). This system enables researchers to collect, analyse and present data in a visual format alongside their geographical information. BIM along with a GIS database can link with data collected from the interviews'/questionnaire's online database. Environmental data from Building Management Systems (BMS), bills and energy metres, and the remote sensing devices can be collected and linked to the spatial data (3D model) provided by Building Information Modelling (Göçer et al., 2015). All collected information can be transferred into a single database and information system. This method can be used to collect and analyse data linked to visual and spatial information. It can offer a sound basis for an efficient building performance monitoring system. Some studies on the usage of a similar method (GIS-based spatial mapping method) helps to draw patterns of user satisfaction and dissatisfaction. It has enabled the diagnosis of building related problems more efficiently and accurately (Hua et al., 2014). This combined method using remote sensors, BIM and a GIS system can be utilised for collecting and analysing both quantitative and qualitative data alongside the visual and spatial representations of data analysis on occupant comfort and satisfaction.

\subsection{Discussion}

This study reviewed the existing literature to outline different IEQ factors that affect occupant productivity in an office environment. This section discusses each IEQ factor and its relevant physical parameters. It aims to discuss each of the IEQ factor and its productivity measurement method to map occupant perception towards the indoor environment.

\subsection{Indoor Air Quality}

One of the earliest works on IAQ was published by (Vernon and Bedford, 1930) who looked at the ventilation of school buildings. The IAQ literature reviewed in this study indicates four areas in IAQ research. These are air quality (constituents and pollutants), ventilation, the effect on human health, and occupant perception and productivity.

The first area focuses on the components and features of indoor air quality. It covers the study of the impact of relative humidity, air temperature, and contaminant level and air movement on humans in an indoor environment. The focus of IAQ research exhibits a trend. It started from research on moisture, air temperature and carbon dioxide levels and later expanded towards pollutants or contaminants present in the indoor air along with studies of their indoor and outdoor sources. The developing trend in IAQ research could be primarily due to overall research and development trends in indoor environment quality and science and technology.

The second area of IAQ research focuses on ventilation in buildings. It is one of the early topics in indoor air quality research (Vernon and Bedford, 1930). Ventilation research moved towards defining the fundamental principles and standards for IAQ (Chrenko, 1974, ASHRAE Standard, 1989). Ventilation systems and their features have been part of IAQ research (ASHRAE Standard, 1989, Seppänen et al., 1999) to provide better ventilation for different types of building (Fisk et al., 2012, Kim and de Dear, 2012, Zhang et al., 2010). The applicability and performance of a ventilation system is highly dependent on the contextual factors like building typology, outside climate, active architectural features in the building.

The third area of the research is the effect of poor indoor air quality on human health and well-being. Human health and well-being have been the primary drivers for research on indoor air quality. SBS (Sick Building Syndrome) and BRI (Building Related Illness) were first documented in the 1980s. It led to indoor air pollutant and contaminant level specifications 
(World Health, 1982, ASHRAE Environmental Health Committee, 1987). Other diseases and effects reviewed were Hypersensitivity Pneumonitis (HP), Occupational Asthma (OA) and Sick Building Syndrome (SBS) (Jones, 1999). It was followed by research on enhancing the understanding of the benefits of healthy office occupants by providing them with good air quality (Dorgan et al., 1998, Wargocki et al., 2000). Volatile Organic Compound (VOC) and aldehydes' presence in indoor air and their discovery of their sources like paints, furniture and other indoor material is the latest and ongoing development related to poor IAQ and its effect on human health.

The fourth research area highlights occupant perception and productivity. The health and well-being of humans were major drivers in the early indoor air quality research. It was in the late 1990s when the first published findings from a series of case studies indicated direct productivity loss due to poor indoor air pollution (Wyon, 2004). Productivity loss due to bad air quality is documented in many research studies (Fisk, 2000a, Kosonen and Tan, 2004, Wyon, 2004, Huizenga et al., 2006, Zheng et al., 2009b). Research conducted on perceived air quality signifies the importance of occupants' perception of healthy indoor air for better work performance (Tham et al., 2015, Kosonen and Tan, 2004).

The literature review also identifies three main physical parameters in IAQ study. These are ventilation rate, indoor pollutant levels and outdoor air monitoring (in a case of low-quality outdoor air). Monitoring these three parameters would help building managers to maintain the healthy indoor air quality of a building. An occupant survey can be used to understand occupants' perceptions as to the existing indoor air quality. A measurement analysis of IAQ parameters along with results from an occupant survey would help to draw an understanding of the preferable range of indoor air quality $($ Table -3$)$.

\begin{tabular}{|c|c|c|}
\hline \multicolumn{3}{|c|}{ Indoor Air Quality } \\
\hline Measurable parameters & Instrument & Occupant Survey \\
\hline Ventilation rate & $\begin{array}{c}\text { Building } \\
\text { Management } \\
\text { system }\end{array}$ & \multirow{3}{*}{$\begin{array}{c}\text { Occupants' perception of the indoor } \\
\text { air quality }\end{array}$} \\
\hline Indoor pollutant level & Sensor & \\
\hline $\begin{array}{l}\text { Outdoor air monitoring } \\
\text { (pollutant level) }\end{array}$ & Sensor & \\
\hline
\end{tabular}

Table 3- IAQ measurement method

\subsection{Thermal Comfort}

This review of the literature on thermal comfort has summarised the theoretical and practical research undertaken on thermal comfort in the built environment. There is a broad range of literature available on thermal comfort from the past 50 years. Fanger's (1984) and Macpherson's (1962) research mark early fundamental studies in this field. The review highlights two facets of thermal comfort. First, the tangible conditions and factors (mean radiant temperature, relative humidity, and air temperature) which define the thermal state. The second facet is the human aspect. It constitutes human perception, acception, and preference towards the thermal state. A thermal state can trigger a diverse range of human responses, iterating the subjective nature of thermal comfort. It is highly dependent on occupants' age, gender, metabolic rate, clothing, and activity pattern (sedentary or steady conditions), and regional weather. However, there is ample evidence to define a temperature range that is favourable for office occupants to perform the majority of tasks efficiently.

The literature review underlines two major thermal comfort approaches, Fanger's (Fanger, 1970) rational approach and De Dear's (De Dear et al., 1997) adaptive approach. Both methods have respective potentialities and limitations. The rational approach provides a 
good prediction of thermal sensation but lacks in actual thermal sensation. The adaptive approach considers more practical factors such as human behaviour and adaptations of humans, within field studies. It highlights geographical variance of comfortable temperature due to factors like contextual climate conditions, dress code in an organisation. Personal control and local task conditioning system are also major areas of thermal comfort discussion. The selection of these methods should be based on the indoor conditions of the target environment.

Thermal comfort standards and references are a good starting point for heating and ventilation system design for an indoor environment. However, one should consider the regional climate factors and occupant behaviour patterns when determining the thermal comfort range for a building in a particular geographical condition.

The literature review recommends measurement four physical parameters; radiant temperature, relative humidity, air temperature and velocity. These parameters can be measured using sensors. Online survey is a useful method for collecting human responses to the thermal state. It is recommended to map occupant profiles by including questions eliciting details such as age, sex and activity patterns in the survey to draw an analysis of an occupant's profile (Table - 4). This information would provide data for a comparison analysis based on occupants and their thermal preferences. The analysis of the physical measurements and the survey would help to understand the thermal comfort of the occupants.

\begin{tabular}{|c|c|c|c|}
\hline \multicolumn{4}{|c|}{ Thermal Comfort } \\
\hline $\begin{array}{l}\text { Measurable } \\
\text { parameters }\end{array}$ & Instrument & \multicolumn{2}{|c|}{ Occupant Survey } \\
\hline Radiant temperature & Sensor & Sex & \multirow{4}{*}{$\begin{array}{l}\text { Occupant Response } \\
\text { - Too cold } \\
\text { - Cold } \\
\text { - Satisfactory/neutral } \\
\text { - Hot } \\
\text { - Too hot }\end{array}$} \\
\hline Relative humidity & Sensor & Age & \\
\hline $\begin{array}{c}\text { Air (temperature and } \\
\text { movement) }\end{array}$ & Sensor & Metabolic rate & \\
\hline Clothing insulation & Calculation & Activity pattern & \\
\hline
\end{tabular}

Table 4 - Thermal Comfort measurement method

\subsection{Lighting and Daylighting}

The literature review helps to draw up an understanding of daylighting and lighting fundamentals and strategies that affect occupant productivity. It highlights different industry standards and measurement methods to control lighting in the indoor environment.

Daylighting and Lighting design in a building should be designed strategically to achieve comfortable lighting levels for the human eye. Different types of activities require different lighting levels. Ambient and task lighting should be designed separately according to the required lux levels for respective office tasks and the required lux levels for ambient lighting. A good lighting system should harvest the maximum amount of available sunlight to reduce the artificial lighting energy load. It is recommended to incorporate daylighting factor, glare index and illuminance values when developing daylight design for an indoor environment. Contextual factors like solar altitude, solar radiation, window direction, outside temperature, season and time of the day modifies human behaviour towards lighting comfort. Literature also recommends reviewing traditional and vernacular architecture to develop simple yet effective lighting design strategies. It would lead to a positive increment in occupants' mood, satisfaction and productivity alongside lower energy consumption. 
The study indicates three factors that contribute to maintaining healthy indoor lighting levels. These are the luminance level, the daylight and artificial light ratio and the glare index.

\begin{tabular}{|c|l|l|}
\hline \multicolumn{2}{|c|}{ Lighting and Daylighting } \\
\hline Measurable parameters & Instrument & Occupant Survey \\
\hline $\begin{array}{c}\text { Luminance level (ambient } \\
\text { and desk) }\end{array}$ & Lighting Sensor & \\
\cline { 1 - 2 } $\begin{array}{c}\text { Daylight and artificial light } \\
\text { ratio }\end{array}$ & $\begin{array}{l}\text { Sensor and } \\
\text { Calculation }\end{array}$ & Occupants' response to indoor lighting \\
\hline Glare index & Calculation & \\
\hline
\end{tabular}

Table 5 - Lighting and daylighting measurement method

The lighting and daylighting of an indoor environment can be measured using light sensors and mathematical calculations can be used for the glare index. Alongside these measurements, occupants' response on current indoor lighting can be collected using an online survey (Table -5). An analysis of both these methods would enable the determination of the occupants' preferred lighting setting in an indoor environment.

\subsection{Noise and Acoustics}

The literature review establishes the relationship between the sound levels of an indoor environment and its occupants' productivity. Acoustic strategy depends on two factors: the internal noise level and the external noise level. A building structure and envelope should be designed to minimise the disruption from external noise. The acoustic strategy for internal noise in an office depends on the layout of the office environment alongside its organisational structure, workforce tasks, and technology. Depending on a workforce's daily process, an organisation may be required to choose between an open-plan and a cellular plan office to manage internal sound levels. The acoustic design should incorporate basic sound masking and the industry level recommendations for sound insulation and absorption. Sound and acoustic strategies should be given high priority in office design to achieve a high degree of occupant productivity.

The study suggests observing and monitoring indoor and outdoor sound levels. It is recommended to compare the observed sound levels to the regional industry standard for an indoor office environment. An occupant survey can be used to draw an understanding of occupants' responses to the existing sound levels. An analysis of the recorded and recommended sound levels along with the occupants' responses would help to determine the comfort range of the noise factor for office occupants (Table -6).

\begin{tabular}{|c|c|c|}
\hline \multicolumn{2}{|c|}{ Noise and Acoustics } \\
\hline Measurable parameters & Instrument & Occupant Survey \\
\hline Indoor sound level & Decibel sensor & $\begin{array}{c}\text { Occupants' response to noise level } \\
\text { in the office }\end{array}$ \\
\hline Outdoor sound level & Decibel sensor & \begin{tabular}{c} 
Och \\
\hline
\end{tabular}
\end{tabular}

$\underline{\text { Table } 6 \text { - Noise and acoustic level measurement method }}$

\subsection{Office Layout}

The literature reviewed indicates the importance of an office layout for achieving productivity in an office environment. Significant focus has been placed on the debate concerning open plan and cellular offices. The literature supports mix mode offices that have the features of both open-plan and cellular office plan depending on office requirements. 
Business organisations are changing rapidly. Organisational and operational changes in companies are occurring more frequently as compared to the cycle of change 20 years ago. These changes bring functional and behavioural changes into an organisation and its workforce. Apart from providing comfort and privacy to its occupants, the workplace should be designed to accommodate the core operability of an organisation yet be flexible enough to accommodate the peripheral changes in an organisation. A distraction free work environment can be provided by a cellular office or an open plan office using different types of proximity measures and partition measures.

The physical setting and layout is part of organisational culture and it reflects the openness, equality and collective reviewing in an organisation. Literature also suggests that national culture indirectly affects the organisational culture and office layout. A good office design aims to create minimum tension between an organisation's work processes and the office environment. An office plan should seek to replicate workflow in its design in order to enhance employee productivity.

The literature review indicates the significant debate on open plan and cellular offices. The study recommends using a mix mode office design. The mix mode office layout includes features of both open-plan and cellular office plan, depending on office requirements. It is recommended to analyse any office layout by two analyses:

- Office layout and work process analysis

This activity would involve analysing the case study office's design plans against the office work processes/work patterns. It would require a research team to access the work processes of the organisation.

- Open plan, cellular plan or hybrid plan layout

This activity aims to understand the office layout. It would analyse whether the case study office is an open plan, cellular plan or hybrid plan layout. It would also help to determine which type of plan layout would complement the strategies/work processes of the organisation's work procedures.

\begin{tabular}{|c|c|}
\hline \multicolumn{2}{|c|}{ Office Layout } \\
\hline Analysis & Occupant Survey \\
\hline Office layout and work process analysis & \multirow{2}{*}{ Occupants' response to office layout } \\
\cline { 1 - 1 } Open plan, cellular plan or hybrid plan layout & \\
\hline
\end{tabular}

Table 7 - Office Layout analysis method

The literature review suggests gauging occupant response to an office layout by using an online survey. Both the occupant survey and the above mentioned office layout analyses would help to determine the suitability of, and the degree of influence of, the office layout on the occupants (Table -7 ).

\subsection{Biophilia and Views}

The literature review sought the highlights of the human relationship with nature. Our association and satisfaction with indoor space is influenced by the inclusion of nature around us. Office design development should include biophilic design features from the concept design stage in the design process. A greater connection with nature would yield higher productivity results in an office environment. Biophilic design strategy can be used to infuse natural life into the office environment. The literature highlights two approaches to measuring biophilia features in an office:

- Views of nature and greenery when looking outside from a building. 
Map the views available to the occupant. The activity also requires identifying any biophilia available in the views.

- Biophilia features inside the building.

Identify biophilia features like plants, water features, and analogue biomorphic forms representing biophilia design features.

The results from the above analysis can be analysed along with the results from occupant survey about the presence/absence of biophilia and the occupants' opinions about the existing outdoor views (Table -8 ).

\begin{tabular}{|c|c|}
\hline \multicolumn{2}{|c|}{ Biophilia and views } \\
\hline Analysis & Occupant Survey \\
\hline $\begin{array}{l}\text { Documenting outside views - presence of } \\
\text { greenery, bodies of water }\end{array}$ & Occupants' response to presence/absence of nature \\
\hline $\begin{array}{l}\text { Documenting biophilia characteristics in } \\
\text { the office design }\end{array}$ & Occupants' response to biophilia features in the office \\
\hline
\end{tabular}

Table 8 - Biophilia and views' analysis method

\section{$\underline{7.7 \text { Look and Feel }}$}

Colour schemes, spatial features and the textures of indoor environments constitute the aesthetical appeal of a space. The definition of the 'look and feel' of a workplace is subjective and depends both on social norms and personal preferences. A good office design would aim to understand and address an organisation's aesthetical outlook and values in the workplace design strategy. The 'look and feel' of a workplace can influence the employees' feeling of well-being and performance. Hence, it is also necessary to address the employees' aesthetical expectations and preferences in the workplace design strategy.

It is recommended to analyse three design features in an office:

1. Developing an understanding of the colour palette used in the office layout. The liking and acceptance of a colour palette can be defined using an occupant survey.

2. An office design strategy should aim to reflect an organisation's brand, culture and values in its office design.

3. The spatial setting of an office design affects occupants' comfortability in an office, resulting in influencing the work patterns of the occupants.

\begin{tabular}{|c|c|}
\hline \multicolumn{2}{|c|}{ Look and Feel } \\
\hline Analysis & Occupant Survey \\
\hline $\begin{array}{c}\text { Colour palette analysis } \\
\text { Organisation brand and office design } \\
\text { analysis }\end{array}$ & $\begin{array}{c}\text { Occupants' response to the appeal of the office } \\
\text { design }\end{array}$ \\
\hline $\begin{array}{c}\text { Spatial settings } \\
\text { Sn }\end{array}$ \\
\hline
\end{tabular}

Table 9 - 'Look and Feel' analysis method

The 'Look and Feel' factor can be analysed using an occupants' survey. The study suggests including questions focusing on indoor environment's aesthetics in the occupant survey. It would help to understand the impact of the look and feel factor within an office on occupant comfort and productivity (Table -9). 


\subsection{Location and Amenities}

The literature indicates that a convenient office location (with transport accessibility and proximity to various amenities) could help to improve office productivity and the well-being of employees. Organisations are recommended to provide healthcare, childcare and health centres for their employee in order to gain long-term benefits from higher productivity and employee retention.

It indicates five parameters under the location and amenities factor. These are proximity to public transport facilities, healthcare/clinic facilities, childcare facilities, recreational space and sports facilities, and entertainment facilities (Table - 10).

\begin{tabular}{|c|c|c|}
\hline \multicolumn{3}{|c|}{ Location and Amenities } \\
\hline Analysis & Instrument & Occupant Survey \\
\hline Proximity to public transport facility & \multirow{5}{*}{$\begin{array}{c}\text { Distance } \\
\text { analysis using } \\
\text { Google Map }\end{array}$} & \multirow{5}{*}{$\begin{array}{l}\text { Occupants' response to location and } \\
\text { amenities around the office. }\end{array}$} \\
\hline Proximity to healthcare/clinic facility & & \\
\hline Proximity to childcare facility & & \\
\hline $\begin{array}{l}\text { Proximity to recreational space \& } \\
\text { sports facility }\end{array}$ & & \\
\hline Proximity to entertainment facility & & \\
\hline
\end{tabular}

Table 10 - Location and amenities' analysis method

The above section provided an elaborate discussion on each IEQ factor. This method can be used to map occupant's reaction an indoor envionrment. It would help to achieve the comfortable setting to help increase occupant productivity.

The literature also suggests measuring employee productivity using indirect objective methods such as absenteeism, the number of hours worked (weekly) and employee turnover. These methods should be analysed alongside an overall occupant survey to establish occupants' comfort and productivity in a physical office environment.

\subsection{Conclusion}

This study reviewed a broad range of literature available on occupant comfort and occupant productivity in the built environment. It analysed different indoor environmental factors that affect occupant comfort and productivity. The literature review illustrates both the financial and health benefits of a healthy indoor environment. The study also shows the significance of the impact of the physical and behavioural environment on occupant comfort and productivity. 


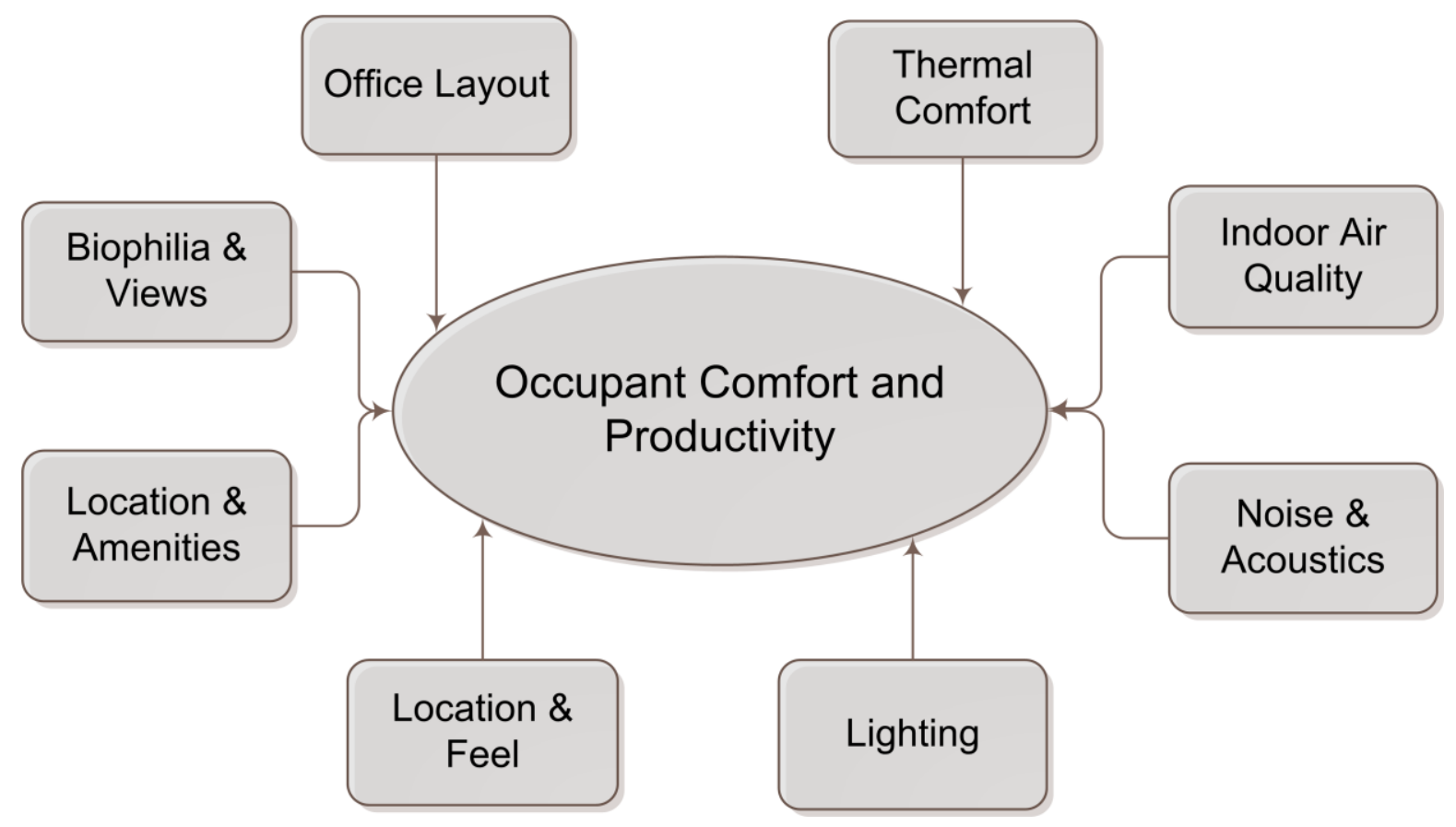

Figure $3-\mathrm{IEQ}$ factors and Occupant Productivity

This literature review has highlighted eight physical factors (Figure - 6) that affect Indoor Environmental Quality (IEQ) and occupant productivity. Thermal comfort, indoor air quality, office layout, and noise and acoustics were found to be highly significant in affecting occupant productivity. A broad range of case studies and the literature indicate a high correlation between these factors and occupant productivity. There are interactions and correlation between these IEQ factors as well. The review suggest clear interaction between daylighting and thermal comfort, thermal comfort and indoor air quality, 'look and feel' and views, and office layout and acoustic properties of an indoor environment. This review can be taken as starting point to develop experiments to look at magnitude and impacts of various interactions between these IEQ factors.

The literature review also draws attention towards the complexity of understanding, measuring and achieving occupant productivity in an office environment. Occupant comfort directly relates to the physical factors of the indoor environment. Comfort is a response to the physical state created by the combined effect of the physical characteristics of the environment. Industry standards from different countries recommend different acceptable levels for the physical attributes in an indoor environment. However, these recommended levels have received a broad spectrum of occupant acceptance and response in various surveys. The study indicates that there is no point measurement for comfort, but there is a comfort zone for each factor.

The complexity of defining and achieving comfort has two facets. Firstly, there is a need to identify the comfort zone of each physical factor and to achieve the comfort zone of the overall physical state. Secondly, there is the complexity of the occupants' response to the overall physical state. Occupant comfort is highly subjective and depends on various independent personal variables such as individual metabolism, clothing preference, activity patterns and the localised conditions of different zones inside an office. The study has tried to identify these two facets of comfort for each of the identified IEQ physical factors.

The majority of green building rating systems acknowledge the effect of indoor environment quality on occupant productivity but do not explicitly award credits for focusing on occupant productivity. This study can be used as a base study to develop green building ratings further to craft criteria focusing occupant productivity. The study highlights potential future 
opportunities to manage building performance according to occupant's preference. Building's indoor environment state can be monitored using wireless sensors connected to building management system and employee/occupant response can be captured using survey. This monitoring system coupled with online databases can allow companies to have efficient employee management by the human resource department. It would enable a company to map world-wide performance and improve their assets' (buildings) performance as well as increase their global productivity.

The advancement in technology on Building Information Modelling (spatial mapping), cloud computing, remote access technology, big data analysis and sophisticated sensors and simulation tools can be applied to develop new research initiatives in order to look at occupant productivity and IEQ factors in greater depth. We can use these technologies to look at benchmarking performance of occupants in different buildings and develop best practice design for architects, engineers and designers.

The review also suggests that culture and values (organisational, national) have implicit effect on characteristics and norms of the indoor environment quality. This also influences occupant productivity. It provides an opportunity for researchers working in the area of sociology, business management and built environment to investigate this new thread of research. The review also underlines the importance of contextual and vernacular characteristics while designing an indoor environment for employees. It includes various dimensions of physical climate and social climate of the context. Most of the reviewed IEQ factors indicated the significant impact of contextual parameters on the IEQ factors and provide elevated occupant comfort and satisfaction. Future research endeavour can be directed towards investigating the relationship and degree of impact of contextual factors on IEQ factors.

This state-of-the art paper gives a comprehensive analysis of occupant productivity and the indoor physical environment. It brings together literature from vast knowledge area. In the future, architects and building engineers need to understand these IEQ factors and their impact on occupant productivity in order to design better buildings. The future objective is to examine how the current sustainability standards and rating systems worldwide may interact with occupant comfort and the productivity within buildings. All the related IEQ parameters need to be studied in order ensure that these guidelines provide the optimum conditions for an indoor environment over the whole year and during the whole building life span.

\subsection{Acknowledgment}

This research is supported by the Qatar National Research Funding under the project "GSAS Guidelines for Occupant Performance, Health and Environmental Realization of Sustainability" under the acronym GOPHERS and NPRP No.: 7 - 344 - 2 - 146.

\subsection{References}

2009. UNEP SBCI. Buildings and Climate - Summary for Decision Makers. United Nations Environment Programme.

2011. Managing Presenteeism. www.centreformentalhealth.org.uk: UK Centre for Mental Health. (AMA), A. M. A. 2004. AMA Workware Toolkit: Case Study Department of Health Office Evaluation. ABBASZADEH, S., ZAGREUS, L., LEHRER, D. \& HUIZENGA, C. 2006. Occupant satisfaction with indoor environmental quality in green buildings. Center for the Built Environment.

ABDOU, O. A. 1997. Effects of luminous environment on worker productivity in building spaces. Journal of architectural engineering, 3, 124-132. 
ABOULNAGA, M. M. 2006. Towards green buildings: Glass as a building element-the use and misuse in the gulf region. Renewable Energy, 31, 631-653.

AKIMOTO, T., TANABE, S.-I., YANAI, T. \& SASAKI, M. 2010a. Thermal comfort and productivityEvaluation of workplace environment in a task conditioned office. Building and Environment, 45, 45-50.

AKIMOTO, T., TANABE, S.-I., YANAI, T. \& SASAKI, M. 2010b. Thermal comfort and productivity Evaluation of workplace environment in a task conditioned office. Building and Environment, $45,45-50$.

AL-ESIA, Z. \& SKOK, W. 2015. Arab knowledge sharing in a multicultural workforce: a dual case study in the UAE. Arabian Journal of Business and Management Review, 2015.

ALRUBAIH, M. S., ZAIN, M. F. M., ALGHOUL, M. A., IBRAHIM, N. L. N., SHAMERI, M. A. \& ELAYEB, O. 2013. Research and development on aspects of daylighting fundamentals. Renewable and Sustainable Energy Reviews, 21, 494-505.

ANDER, G. D. 2003. Daylighting performance and design, John Wiley \& Sons.

ARIES, M. B. C. 2005. Human lighting demands: healthy lighting in an office environment. Technische Universiteit Eindhoven.

ARIES, M. B. C., VEITCH, J. A. \& NEWSHAM, G. R. 2010. Windows, view, and office characteristics predict physical and psychological discomfort. Journal of Environmental Psychology, 30, 533 541.

ASHER, C. B. 1992. Architecture of Mughal India, Cambridge University Press.

ASHRAE 1993. Fundamentals, ASHRAE. Atlanta.

ASHRAE 2004. Standard 55-2004, Thermal environmental conditions for human occupancy. American Society of Heating, Refrigerating and Air-Conditioning Engineering, Atlanta, GA.

ASHRAE 2005. ASHRAE handbook of fundamentals. American Society of Heating, Refrigerating and Air Conditioning Engineers. Atlanta, Georgia, USA: ASHRAE.

ASHRAE 2010. ASHRAE Standard 55. Thermal Environmental Conditions for Human Occupancy. Atlanta: Inc.

ASHRAE ENVIRONMENTAL HEALTH COMMITTEE 1987. Indoor Air Quality Position Paper. Atlanta, GA: American Society of Heating, Refrigeration, and AirConditioning Engineers.

ASHRAE STANDARD 1989. Standard 62-1999, Ventilation for Acceptable Indoor Air Quality. American Society of Heating, Refrigerating, and Air-Conditioning Engineers, Inc., Atlanta, Ga.

ASHRAE STANDARD 1992. Standard 55-1992. Thermal environmental conditions for human occupancy.

ASHRAE STANDARD 2004. Standard 55-2004. Thermal environmental conditions for human occupancy.

ASSOCIATION, A. C. 2011. An introduction to indoor air quality (IAQ): Volatile Organic Compounds (VOCs), Washington DC, USA; 2011.

AYR, U., CIRILLO, E., FATO, I. \& MARTELLOTTA, F. 2003. A new approach to assessing the performance of noise indices in buildings. Applied Acoustics, 64, 129-145.

BALAZOVA, I., CLAUSEN, G., RINDEL, J. H., POULSEN, T. \& WYON, D. P. 2008. Open-plan office environments: a laboratory experiment to examine the effect of office noise and temperature on human perception, comfort and office work performance. Proceedings of indoor air, 2008.

BANBURY, S. \& BERRY, D. 2005. Office noise and employee concentration: Identifying causes of disruption and potential improvements. Ergonomics, 48, 25-37.

BARCLAY, L. A. \& YORK, K. M. 2001. Space at work: exercises in the art of understanding physical indicators of culture. Journal of Management Education, 25, 54-69.

BAUMAN, F., CARTER, T. \& BAUGHMAN, A. 1998. Field study of the impact of a desktop task/ambient conditioning system in office buildings. Center for the Built Environment.

BAUMAN, F. S. P. E. \& ARENS, E. A. P. D. 1996. Task/ambient conditioning systems: Engineering and application guidelines. 
BERENJIAN, A., CHAN, N. \& MALMIRI, H. J. 2012. Volatile organic compounds removal methods: a review. Am J Biochem Biotechnol, 8, 220-229.

BERGLUND, B., HASSMEN, P. \& JOB, R. S. 1996. Sources and effects of low-frequency noise. The Journal of the Acoustical Society of America, 99, 2985-3002.

BERGLUND, L. Mathematical models for predicting thermal comfort response of building occupants. Ashrae Journal-American Society of Heating Refrigerating and Air-Conditioning Engineers, 1977. AMER SOC HEAT REFRIG AIR-CONDITIONING ENG INC 1791 TULLIE CIRCLE NE, ATLANTA, GA 30329, 38-38.

BISCHOF, W. \& BULLINGER, M. 1998. Indoor Conditions and Well-Being: Interim Results from the ProKlimA Study. Indoor and Built Environment, 7, 232-233.

BLUYSSEN, P. M., ARIES, M. \& VAN DOMMELEN, P. 2011. Comfort of workers in office buildings: The European HOPE project. Building and Environment, 46, 280-288.

BLUYSSEN, P. M., DE OLIVEIRA FERNANDES, E., GROES, L., CLAUSEN, G., FANGER, P. O., VALBJØRN, O., BERNHARD, C. A. \& ROULET, C. A. 1996. European Indoor Air Quality Audit Project in 56 Office Buildings. Indoor Air, 6, 221-238.

BOAKE, T. M., BES, B. \& ARCH, M. 2014. Hot climate Double Facades: Avoiding Solar Gain.

BORDASS, B., BROMLEY, K. \& LEAMAN, A. User and occupant controls in office buildings. International conference on building design, technology and occupant well-being in temperate climates, Brussels, Belgium, 1993. 12-5.

BOYCE, P., HUNTER, C. \& HOWLETT, O. 2003. The benefits of daylight through windows. Troy, New York: Rensselaer Polytechnic Institute.

BOYCE, P. R. 1997. Light, sight and photobiology. Lighting Futures, 2.

BRAGER, G. \& BAKER, L. 2009. Occupant satisfaction in mixed-mode buildings. Building Research \& Information, 37, 369-380.

BRAGER, G. S. \& DE DEAR, R. J. 1998. Thermal adaptation in the built environment: a literature review. Energy and Buildings, 27, 83-96.

BRENNAN, A., CHUGH, J. S. \& KLINE, T. 2002. Traditional versus open office design a longitudinal field study. Environment and Behavior, 34, 279-299.

BRENNER, P. \& CORNELL, P. 1994. The balance between privacy and collaboration in knowledge worker teams. Human Factors in Organizational Design and Management., Stockholm, Sweden.

BRIGHT, G. T. 2012. The economics of Biophilia. Why designing with nature in mind makes financial sense. New York (NY): Terrapin Bright Green.

BRILL, M., MARGULIS, S. T. \& KONAR, E. 1985. Using office design to increase productivity, Workplace Design and Productivity, Inc.

BRILL, M. \& WEIDEMANN, S. 2001. Disproving widespread myths about workplace design.

BUSCH, J. F., DU PONT, P. \& CHIRARATTANANON, S. 1993. Energy-efficient lighting in Thai commercial buildings. Energy, 18, 197-210.

BUTLER, D. L. \& BINER, P. M. 1989. Effects of setting on window preferences and factors associated with those preferences. Environment and Behavior, 21, 17-31.

CABE 2005. The impact of Office Design on Business Performance. London: Commission for Architecture \& Built Environment and the British Council for Offices.

CANTIN, F. \& DUBOIS, M.-C. 2011. Daylighting metrics based on illuminance, distribution, glare and directivity. Lighting Research and Technology, 43, 291-307.

CENA, K. \& DE DEAR, R. 2001. Thermal comfort and behavioural strategies in office buildings located in a hot-arid climate. Journal of Thermal Biology, 26, 409-414.

CHACHERE, J., KUNZ, J. \& LEVITT, R. 2003. Can you accelerate your project using extreme collaboration? A model based analysis. Center for Integrated Facility Engineering (CIFE), Stanford University, CIFE Technical Report.

CHANG, C.-Y. \& CHEN, P.-K. 2005. Human response to window views and indoor plants in the workplace. HortScience, 40, 1354-1359. 
CHANG, S. \& MAHDAVI, A. 2002. A hybrid system for daylight responsive lighting control. Journal of the Illuminating Engineering Society, 31, 147-157.

CHAO, C. Y. \& CHAN, G. Y. 2001. Quantification of indoor VOCs in twenty mechanically ventilated buildings in Hong Kong. Atmospheric Environment, 35, 5895-5913.

CHARLES, K. E. 2003. Fanger's thermal comfort and draught models.

CHOI, J., AZIZ, A. \& LOFTNESS, V. Decision support for improving occupant environmental satisfaction in office buildings: The relationship between sub-set of IEQ satisfaction and overall environmental satisfaction. Proceedings of the 9th International Conference Healthy Buildings, Syracuse, NY USA, 2009.

CHRENKO, F. A. 1974. Bedford's Basic Principles of Ventilation and Heating.

CIBSE. 2015. The CIBSE Journal CPD Programme: Lighting control technologies and strategies to cut energy consumption [Online]. CIBSE. [Accessed 12/07/15 2015].

CLEMENTS-CROOME, D. 2006. Creating the productive workplace, Taylor \& Francis.

CLEMENTS-CROOME, D. 2013. Intelligent buildings: an introduction, Routledge.

CLEMENTS-CROOME, D. 2015. Creative and productive workplaces: a review. Intelligent Buildings International, 1-20.

CLEMENTS-CROOME, D. J. 2000. Creating the Productive Workplace.

CLEMENTS-CROOME, D. J. 2004a. Electromagnetic Environments and Health in Buildings.

CLEMENTS-CROOME, D. J. 2004b. Intelligent Buildings: Design, Management \& Operation.

CUTTLE, C. People and windows in workplaces. Proceedings of the people and physical environment research conference, 1983. 47-51.

DAHER, R. F. 1999. Gentrification and the politics of power, capital and culture in an emerging Jordanian heritage industry. Traditional Dwellings and Settlements Review, 33-45.

DANIELSSON, C. B. \& BODIN, L. 2009. Difference in satisfaction with office environment among employees in different office types. Journal of Architectural and Planning Research, 241-257.

DE DEAR, R., BRAGER, G. \& COOPER, D. 1997. Developing an Adaptive Model of Thermal Comfort and Preference.

DE DEAR, R. \& BRAGER, G. S. 1998. Developing an adaptive model of thermal comfort and preference.

DE DEAR, R. J. \& BRAGER, G. S. 2002. Thermal comfort in naturally ventilated buildings: revisions to ASHRAE Standard 55. Energy and buildings, 34, 549-561.

DEAN, J. W., OTTENSMEYER, E. \& RAMIREZ, R. 1997. An aesthetic perspective on organizations. Creating tomorrow's organizations: A handbook for future research in organizational behavior, 419-437.

DENG, X. \& GAO, H. 2010. Do Nonmonetary Benefits Matter for Corporate Executives? Evidence from the Pay Premium for Quality of Life.

DIMITROULOPOULOU, C. \& BARTZIS, J. 2013. Ventilation rates in European office buildings: A review. Indoor and Built Environment, 1420326X13481786.

DJONGYANG, N., TCHINDA, R. \& NJOMO, D. 2010. Thermal comfort: A review paper. Renewable and Sustainable Energy Reviews, 14, 2626-2640.

DORGAN, C. B., DORGAN, C. E., KANAREK, M. S. \& WILLMAN, A. J. 1998. Health and productivity benefits of improved indoor air quality. ASHRAE Transactions, 104, 658.

DOULOS, L., TSANGRASSOULIS, A. \& TOPALIS, F. A critical review of simulation techniques for daylight responsive systems. Proceedings of the European Conference on Dynamic Analysis, Simulation and Testing applied to the Energy and Environmental performance of Buildings DYNASTEE, 2005.

DUFFY, F., LAING, A. \& CRISP, V. 1992. The responsible workplace. Facilities, 10, 9-15.

DYKES, C. \& BAIRD, G. 2013. A review of questionnaire-based methods used for assessing and benchmarking indoor environmental quality. Intelligent Buildings International, 5, 135-149.

EC 2013. EU Energy in Figures - Statistical Pocketbook 2014. Publications Office of the European Union Luxembourg. 
EDWARDS, B. 2006. Courtyard housing: Past, present and future, Taylor \& Francis.

ELZEYADI, I. M. 2011. Daylighting-Bias and Biophilia: Quantifying the Impact of Daylighting on Occupants Health. US Green Building Council. http://www. usgbc. org/sites/default/files/OR10_Daylighting\% 20Bias\% 20and\% 20Biophilia. pdf.

EVANS, G. W., BULLINGER, M. \& HYGGE, S. 1998. Chronic noise exposure and physiological response: A prospective study of children living under environmental stress. Psychological science, 9, 75-77.

EZZELDIN, S. \& REES, S. J. 2013. The potential for office buildings with mixed-mode ventilation and low energy cooling systems in arid climates. Energy and Buildings, 65, 368-381.

FANGER, P. 2000. Indoor air quality in the 21st century: search for excellence. Indoor air, 10, 68-73.

FANGER, P. O. 1970. Thermal Comfort.

FANGER, P. O. 1984. Moderate Thermal Environments Determination of the PMV and PPD Indices and Specification of the Conditions for Thermal Comfort. ISO 7730.

FANGER, P. O. 1988. Introduction of the olf and the decipol units to quantify air pollution perceived by humans indoors and outdoors. Energy and Buildings, 12, 1-6.

FAY, C., REA, M. \& FIGUEIRO, M. 2002. Daylighting and Productivity A Literature Review. Lighting Research Center, Rensselaer Polytechnic Institute, Report of Project" Cross-Cutting R\&D on Adaptive Full-Spectrum Solar Energy Systems for More Efficient and Affordable Use of Solar Energy in Buildings and Hybrid Photo-Bioreactors" sponsored by US Department of Energy.

FEIGE, A., WALLBAUM, H., JANSER, M. \& WINDLINGER, L. 2013. Impact of sustainable office buildings on occupant's comfort and productivity. Journal of Corporate Real Estate, 15, 7-34.

FIELD, C. 2008. Acoustic design in green buildings. Ashrae Journal, 50, 60-70.

FIELD, C. D. \& DIGERNESS, J. 2008. Acoustic design criteria for naturally ventilated buildings. Journal of the Acoustical Society of America, 123, 3814.

FISK, W. J. 2000a. Estimates of potential nationwide productivity and health benefits from better indoor environments: an update. Indoor air quality handbook, 4.

FISK, W. J. 2000b. Health and productivity gains from better indoor environments and their relationship with building energy efficiency. Annual Review of Energy and the Environment, 25, 537-566.

FISK, W. J., BLACK, D. \& BRUNNER, G. 2012. Changing ventilation rates in US offices: Implications for health, work performance, energy, and associated economics. Building and Environment, 47, 368-372.

FISK, W. J., MENDELL, M. J., DAISEY, J. M., FAULKNER, D., HODGSON, A. T., NEMATOLLAHI, M. \& MACHER, J. M. 1993. Phase 1 of the California Healthy Building Study: A Summary. Indoor Air, 3, 246-254.

FISK, W. J., MIRER, A. G. \& MENDELL, M. J. 2009. Quantitative relationship of sick building syndrome symptoms with ventilation rates. Indoor air, 19, 159-165.

FISK, W. J. \& ROSENFELD, A. H. 1997. Estimates of improved productivity and health from better indoor environments. Indoor air, 7, 158-172.

FLEMING, D. 2004. Facilities management: a behavioural approach. Facilities, 22, 35-43.

FONTOYNONT, M. 2014. Daylight performance of buildings, Routledge.

FOUNDATION, R. J. W. 2012. Better transportation options=healthier lives [Online]. Available: http://www.rwjf.org/en/blogs/new-publichealth/2012/10/better transportatio.html?cid=xsh rwif tw [Accessed 2015].

FRONTCZAK, M., SCHIAVON, S., GOINS, J., ARENS, E. A., ZHANG, H. P. D. \& WARGOCKI, P. 2012. Quantitative relationships between occupant satisfaction and satisfaction aspects of indoor environmental quality and building design. International journal of Indoor Environment and Health.

GABAY, H., MEIR, I. A., SCHWARTZ, M. \& WERZBERGER, E. 2014. Cost-benefit analysis of green buildings: An Israeli office buildings case study. Energy and Buildings, 76, 558-564. 
GALASIU, A. D. \& VEITCH, J. A. 2006. Occupant preferences and satisfaction with the luminous environment and control systems in daylit offices: a literature review. Energy and Buildings, $38,728-742$.

GÖÇER, Ö., HUA, Y. \& GÖÇER, K. 2015. Completing the missing link in building design process: Enhancing post-occupancy evaluation method for effective feedback for building performance. Building and Environment, 89, 14-27.

GOLDMAN, R. F. 1999. Extrapolating ASHRAE's comfort model. HVAC\&R Research, 5, 189-194.

GORDON-LARSEN, P., BOONE-HEINONEN, J., SIDNEY, S., STERNFELD, B., JACOBS, D. R. \& LEWIS, C. E. 2009. Active commuting and cardiovascular disease risk: the CARDIA study. Archives of internal medicine, 169, 1216-1223.

GOU, Z., PRASAD, D. \& LAU, S. S.-Y. 2014. Impacts of green certifications, ventilation and office types on occupant satisfaction with indoor environmental quality. Architectural Science Review, 57, 196-206.

GRAY, T. \& BIRRELL, C. 2014. Are biophilic-designed site office buildings linked to health benefits and high performing occupants? International journal of environmental research and public health, 11, 12204-12222.

GRINDE, B. \& PATIL, G. G. 2009. Biophilia: does visual contact with nature impact on health and wellbeing? International Journal of Environmental Research and Public Health, 6, 2332-2343.

GUENTHER, A., HEWITT, C. N., ERICKSON, D., FALL, R., GERON, C., GRAEDEL, T., HARLEY, P., KLINGER, L., LERDAU, M. \& MCKAY, W. 1995. A global model of natural volatile organic compound emissions. Journal of Geophysical Research: Atmospheres, 100, 8873-8892.

GUZOWSKI, M. 2000. Daylighting for sustainable design, McGraw-Hill Professional Publishing.

HAIDER, M., KERR, K. \& BADAMI, M. 2013. Does Commuting Cause Stress? The Public Health Implications of Traffic Congestion. The Public Health Implications of Traffic Congestion (August 2, 2013).

HAN, J., ZHANG, G., ZHANG, Q., ZHANG, J., LIU, J., TIAN, L., ZHENG, C., HAO, J., LIN, J. \& LIU, Y. 2007. Field study on occupants' thermal comfort and residential thermal environment in a hothumid climate of China. Building and Environment, 42, 4043-4050.

HATCH, M. J. 1993. The Dynamics of Organizational Culture. The Academy of Management Review, 18, 657-693.

HAYNES, B. P. 2007a. The impact of the behavioural environment on office productivity. Journal of Facilities Management, 5, 158-171.

HAYNES, B. P. 2007b. Office productivity: a theoretical framework. Journal of Corporate Real Estate, 9, 97-110.

HAYNES, B. P. 2008a. An evaluation of the impact of the office environment on productivity. Facilities, 26, 178-195.

HAYNES, B. P. 2008b. The impact of office layout on productivity. Journal of Facilities Management, 6, 189-201.

HAYNES, B. P. 2009. Research design for the measurement of perceived office productivity. Intelligent Buildings International, 1, 169-183.

HEERWAGEN, J. 2000. Green Buildings, organizational success and occupant producticity. Building Research \& Information, 28, 353-367.

HEERWAGEN, J. 2009. Biophilia, health and well-being. Restorative Commons: Creating Health and Well-being through Urban Landscapes, USDA Forest Service, Pennsylvania, 39-57.

HEERWAGEN, J. \& HASE, B. 2001. Building biophilia: Connecting people to nature in building design. Environmental Design and Construction, 3, 30-36.

HEERWAGEN, J. \& HEERWAGEN, D. 1986. Lighting and psychological comfort. Lighting Design and Application, 16, 47-51.

HEERWAGEN, J. H. 2003. Bio-inspired design: What can we learn from nature. Unpublished manuscript. 
HEERWAGEN, J. H., KAMPSCHROER, K., POWELL, K. M. \& LOFTNESS, V. 2004. Collaborative knowledge work environments. Building research \& information, 32, 510-528.

HEERWAGEN, J. H. \& ORIANS, G. H. 1984. Humans, habitats, and aesthetics. The biophilia hypothesis, 138-172.

HEMPHÄLÄ, H. \& EKLUND, J. 2012. A visual ergonomics intervention in mail sorting facilities: effects on eyes, muscles and productivity. Applied ergonomics, 43, 217-229.

HENSEN, J. L. M. 1991. On the thermal interaction of building structure and heating and ventilating system, Technische Universiteitt Eindhoven.

HODGSON, M. 2000. Sick building syndrome. Occupational medicine (Philadelphia, Pa.), 15, 571.

HOPKINSON, R. G. 1963. Architectural Physics: Lighting.

HOPKINSON, R. G., PETHERBRIDGE, P. \& LONGMORE, J. 1966. Daylighting, Heinemann.

HORIZONS, B. 2004. The Real Savings from Employer Sponsored Child Care: Investment Impact Study Results. Watertown, Mass.: Bright Horizons Family Solutions.

HUA, Y., GÖÇER, Ö. \& GÖÇER, K. 2014. Spatial mapping of occupant satisfaction and indoor environment quality in a LEED platinum campus building. Building and Environment, 79, 124137.

HUIZENGA, C., ABBASZADEH, S., ZAGREUS, L. \& ARENS, E. A. 2006. Air quality and thermal comfort in office buildings: results of a large indoor environmental quality survey. Center for the Built Environment.

HUMPHREYS, M. 1978. Outdoor temperatures and comfort indoors. Batiment International, Building Research and Practice, 6, 92-92.

HUMPHREYS, M. A. 1975. Field studies of thermal comfort compared and applied, Building Research Establishment.

HUMPHREYS, M. A., NICOL, J. F. \& RAJA, I. A. 2007. Field studies of indoor thermal comfort and the progress of the adaptive approach. Advances in Building Energy Research, 1, 55-88.

INDRAGANTI, M., OOKA, R. \& RIJAL, H. B. 2015. Thermal comfort in offices in India: Behavioral adaptation and the effect of age and gender. Energy and Buildings, 103, 284-295.

ISO 2005. 7730: 2005:"Ergonomics of the thermal environment-Analytical determination and interpretation of thermal comfort using calculation of the PMV and PPD indices and local thermal comfort criteria". International Organization for Standardisation, Geneva.

JAHNCKE, H. \& HALIN, N. 2012. Performance, fatigue and stress in open-plan offices: The effects of noise and restoration on hearing impaired and normal hearing individuals. Noise and Health, $14,260$.

JONES, A. P. 1999. Indoor air quality and health. Atmospheric Environment, 33, 4535-4564.

KALLIO, T. J., KALLIO, K.-M. \& BLOMBERG, A. J. 2015. Physical space, culture and organisational creativity - a longitudinal study. Facilities, 33, 389-411.

KAPLAN, R. \& KAPLAN, S. 1989. The experience of nature: A psychological perspective, CUP Archive.

KARJALAINEN, S. 2007. Gender differences in thermal comfort and use of thermostats in everyday thermal environments. Building and environment, 42, 1594-1603.

KARJALAINEN, S. 2012. Thermal comfort and gender: a literature review. Indoor Air, 22, 96-109.

KELLERT, S. R., HEERWAGEN, J. \& MADOR, M. 2011. Biophilic design: the theory, science and practice of bringing buildings to life, John Wiley \& Sons.

KELLERT, S. R., HEERWAGEN, J. H. \& MADOR, M. L. 2008. Biophilic design. See http://www. biophilicdesign. net/(accessed on July 8, 2012.).

KESWICK, M., JENCKS, C. \& HARDIE, A. 2003. The Chinese garden: history, art and architecture, Harvard University Press.

KIM, J. \& DE DEAR, R. 2012. Impact of different building ventilation modes on occupant expectations of the main IEQ factors. Building and Environment, 57, 184-193.

KIM, J. \& DE DEAR, R. 2013. Workspace satisfaction: The privacy-communication trade-off in openplan offices. Journal of Environmental Psychology, 36, 18-26. 
KIM, J., DE DEAR, R., CÂNDIDO, C., ZHANG, H. \& ARENS, E. 2013. Gender differences in office occupant perception of indoor environmental quality (IEQ). Building and Environment, 70, 245-256.

KIM, Y. M., HARRAD, S. \& HARRISON, R. M. 2001. Concentrations and sources of VOCs in urban domestic and public microenvironments. Environmental science \& technology, 35, 997-1004.

KOSONEN, R. \& TAN, F. 2004. The effect of perceived indoor air quality on productivity loss. Energy and Buildings, 36, 981-986.

KRARTI, M., ERICKSON, P. M. \& HILLMAN, T. C. 2005. A simplified method to estimate energy savings of artificial lighting use from daylighting. Building and Environment, 40, 747-754.

KRČMÁŘOVÁ, J. 2009. EO Wilson's concept of biophilia and the environmental movement in the USA. Kladyán, 6, 4-17.

KWALLEK, N., LEWIS, C. M. \& ROBBINS, A. S. 1988. Effects of Office Interior Color on Workers' Mood and Productivity. Perceptual and Motor Skills, 66, 123-128.

KWOK, A. G. \& RAJKOVICH, N. B. 2010. Addressing climate change in comfort standards. Building and Environment, 45, 18-22.

L EDWARDS, P. T. 2000. A literature review of the effects of natural light on building occupants.

LAET, I. D., MEYNEN, G., VANUYTSEL, P., TAEYMANS, G. \& ZONNEVELDT, L. User acceptance study of the EE-SYLK daylighting system. Right Light conference, 2002 Nice, France. 93-97.

LAING, A., DUFFY, F., JAUNZENS, D. \& WILLIS, S. 1998. New Environments for Working: The Re-Design of Offices and Environmental Systems for New Ways of Working, London, Construction Research Communications.

LAMPROULIS, D. 2007. Cultural space and technology enhance the knowledge process. Journal of Knowledge Management, 11, 30-44.

LAN, L., WARGOCKI, P. \& LIAN, Z. 2011. Quantitative measurement of productivity loss due to thermal discomfort. Energy and Buildings, 43, 1057-1062.

LANGER, S. \& BEKÖ, G. 2013. Indoor air quality in the Swedish housing stock and its dependence on building characteristics. Building and Environment, 69, 44-54.

LANGEVIN, J., WEN, J. \& GURIAN, P. L. 2013. Modeling thermal comfort holistically: Bayesian estimation of thermal sensation, acceptability, and preference distributions for office building occupants. Building and Environment, 69, 206-226.

LEAMAN, A. 1995. Dissatisfaction and office productivity. Facilities, 13, 13-19.

LEAMAN, A. \& BORDASS, B. 1999. Productivity in buildings: the 'killer' variables. Building Research \& Information, 27, 4-19.

LEAMAN, A. \& BORDASS, B. 2001. Assessing building performance in use 4: the Probe occupant surveys and their implications. Building Research \& Information, 29, 129-143.

LEE, W. 2013. A comprehensive review of metrics of building environmental assessment schemes. Energy and Buildings, 62, 403-413.

LEE, Y. S. 2010. Office layout affecting privacy, interaction, and acoustic quality in LEED-certified buildings. Building and Environment, 45, 1594-1600.

LEE, Y. S. \& GUERIN, D. A. 2009. Indoor environmental quality related to occupant satisfaction and performance in LEED-certified buildings. Indoor and Built Environment, 18, 293-300.

LESLIE, R. 2003. Capturing the daylight dividend in buildings: why and how? Building and Environment, 38, 381-385.

LEVERMORE, G. J., LOWE, D. J. \& URE, J. W. 1999. Occupant feedback questionnaire producing a fingerprint and a score. ASHRAE Transactions, 105, 661.

LI, D. H. 2010. A review of daylight illuminance determinations and energy implications. Applied Energy, 87, 2109-2118.

LI, D. H. W. \& LAM, J. C. 2001. Evaluation of lighting performance in office buildings with daylighting controls. Energy and Buildings, 33, 793-803.

LI, D. H. W. \& TSANG, E. K. W. 2008. An analysis of daylighting performance for office buildings in Hong Kong. Building and Environment, 43, 1446-1458. 
LIM, Y.-W., KANDAR, M. Z., AHMAD, M. H., OSSEN, D. R. \& ABDULLAH, A. M. 2012. Building façade design for daylighting quality in typical government office building. Building and Environment, 57, 194-204.

LIN, Z. \& DENG, S. 2008. A study on the thermal comfort in sleeping environments in the subtropics-Developing a thermal comfort model for sleeping environments. Building and Environment, 43, 70-81.

LINDAHL, G. A. 2004. The innovative workplace: an analytical model focusing on the relationship between spatial and organisational issues. Facilities, 22, 253-258.

LOHR, V. I., PEARSON-MIMS, C. H. \& GOODWIN, G. K. 1996. Interior plants may improve worker productivity and reduce stress in a windowless environment. Journal of Environmental Horticulture, 14, 97-100.

LOPEZ, S. L. The Remittance House: Architecture of Migration in Rural Mexico. Buildings \& Landscapes: Journal of the Vernacular Architecture Forum, 2010. University of Minnesota Press, 33-52.

LORSCH, H. G. \& ABDOU, O. A. 1994. The impact of the building indoor environment on occupant productivity--part 1: recent studies, measures, and costs. ASHRAE Transactions-American Society of Heating Refrigerating Airconditioning Engin, 100, 741-749.

LYONS, P., ARASTEH, D. \& HUIZENGA, C. 2000. Window performance for human thermal comfort. TRANSACTIONS-AMERICAN SOCIETY OF HEATING REFRIGERATING AND AIR CONDITIONING ENGINEERS, 106, 594-604.

MACKERRON, G. \& MOURATO, S. 2013. Happiness is greater in natural environments. Global Environmental Change, 23, 992-1000.

MACPHERSON, R. 1962. The assessment of the thermal environment. A review. British journal of industrial medicine, 19, 151-164.

MACPHERSON, R. 1973. Thermal stress and thermal comfort. Ergonomics, 16, 611-622.

MAHER, A. \& VON HIPPEL, C. 2005. Individual differences in employee reactions to open-plan offices. Journal of Environmental Psychology, 25, 219-229.

MAHNKE, F. H. 1996. Color, environment, and human response: an interdisciplinary understanding of color and its use as a beneficial element in the design of the architectural environment, John Wiley \& Sons.

MANNING, M. A. 2006. An Experimental Evaluation and Comparison of Four Daylighting Strategies for Schools in North Carolina.

MARANS, R. W. \& YAN, X.-Y. 1989. LIGHTING QUALITY AND ENVIRONMENTAL SATISFACTION IN OPEN AND ENCLOSED OFFICES. Journal of Architectural and Planning Research, 6, 118-131.

MASLOW, A. H. 1943. Psychology Review, 50, 370.

MAWSON, A. 2002. The Workplace and Its Impact on Productivity, London, Advance Workplace Associates.

MCCOY, J. M. 2002. Work environments. Handbook of environmental psychology, 443-460.

MCGRAW-HILL CONSTRUCTION 2014. The drive toward healthier Buildings: The market Drivers and Impact of Building Design and Construction on Occupant Health, Well-being and Productivity.

MENDELL, M. J. 1993. Non-Specific Symptoms In Office Workers: A Review And Summary Of The Epidemiologic Literature. Indoor Air, 3, 227-236.

MENDELL, M. J., FISK, W. J., KREISS, K., LEVIN, H., ALEXANDER, D., CAIN, W. S., GIRMAN, J. R., HINES, C. J., JENSEN, P. A., MILTON, D. K., REXROAT, L. P. \& WALLINGFORD, K. M. 2002. Improving the Health of Workers in Indoor Environments: Priority Research Needs for a National Occupational Research Agenda. American Journal of Public Health, 92, 1430-1440.

MILLER, N. G., POGUE, D., GOUGH, Q. D. \& DAVIS, S. M. 2009. Green Building and Productivity. Journal of Sustainable Real Estate, 1, 65.

MOEZZI, M. 2009. Are comfort expectations of building occupants too high? Building Research \& Information, 37, 79-83. 
MORGAN, C. \& DE DEAR, R. 2003. Weather, clothing and thermal adaptation to indoor climate. Climate Research, 24, 267-284.

MUHAISEN, A. S. \& GADI, M. B. 2006. Effect of courtyard proportions on solar heat gain and energy requirement in the temperate climate of Rome. Building and Environment, 41, 245-253.

MUI, K. \& WONG, L. 2006. A method of assessing the acceptability of noise levels in air-conditioned offices. Building Services Engineering Research and Technology, 27, 249-254.

NABHAN, G. P., ST ANTOINE, S., KELLERT, S. \& WILSON, E. 1993. The loss of floral and faunal story: The extinction of experience. The biophilia hypothesis, 229-250.

NAGY, E., YASUNAGA, S. \& KOSE, S. 1995. Japanese office employees' psychological reactions to their underground and above-ground offices. Journal of environmental psychology, 15, 123-134.

NE'EMAN, E. 1970. Critical minimum acceptable window size: a study of window design and provision of a view.

NG, L. C., MUSSER, A., PERSILY, A. K. \& EMMERICH, S. J. 2012. Indoor air quality analyses of commercial reference buildings. Building and Environment, 58, 179-187.

NICOL, F. 2004. Adaptive thermal comfort standards in the hot-humid tropics. Energy and Buildings, 36, 628-637.

NICOL, F., HUMPHREYS, M. \& ROAF, S. 2012. Adaptive Thermal Comfort: Principles and Practice.

NICOL, J. F. \& HUMPHREYS, M. A. 1973. Thermal comfort as part of a self-regulating system.

NICOL, J. F. \& HUMPHREYS, M. A. 2002. Adaptive thermal comfort and sustainable thermal standards for buildings. Energy and buildings, 34, 563-572.

NISIFOROU, O. A., POULLIS, S. \& CHARALAMBIDES, A. G. 2012. Behaviour, attitudes and opinion of large enterprise employees with regard to their energy usage habits and adoption of energy saving measures. Energy and Buildings, 55, 299-311.

OGBONNA, A. C. \& HARRIS, D. J. 2008. Thermal comfort in sub-Saharan Africa: Field study report in Jos-Nigeria. Applied Energy, 85, 1-11.

OLESEN, B. W. \& PARSONS, K. C. 2002. Introduction to thermal comfort standards and to the proposed new version of EN ISO 7730. Energy and Buildings, 34, 537-548.

OMER, A. M. 2008. Energy, environment and sustainable development. Renewable and sustainable energy reviews, $12,2265-2300$.

OSELAND, N. 1999. Environmental Factors Affecting Office Worker Performance: A Review of Evidence, London, CIBSE.

OSELAND, N. 2004. Occupant feedback tools of the office productivity network. Assessed http://www. officeproductivity. co. uk.

OSELAND, N. \& BARTLETT, P. 1999. Improving office productivity: A guide for business and facilities managers, Longman.

OU, L. C., LUO, M. R., WOODCOCK, A. \& WRIGHT, A. 2004. A study of colour emotion and colour preference. part II: colour emotions for two-colour combinations. Color Research \& Application, 29, 292-298.

ÖZTÜRK, E., YILMAZER, S. \& URAL, S. E. 2012. The effects of achromatic and chromatic color schemes on participants' task performance in and appraisals of an office environment. Color Research \& Application, 37, 359-366.

OZTURK, Z., ARAYICI, Y. \& COATES, S. 2012. Post occupancy evaluation (POE) in residential buildings utilizing BIM and sensing devices: Salford energy house example.

PANAGIOTARAS, D., NIKOLOPOULOS, D., KOULOUGLIOTIS, D., PETRAKI, E., ZISOS, I., YIANNOPOULOS, A., BAKALIS, A. \& ZISOS, A. 2013. Indoor Air Quality Assessment: Review on the topic of VOCs.

PANAGIOTARAS, D., NIKOLOPOULOS, D., PETRAKI, E., KOTTOU, S., KOULOUGLIOTIS, D., YANNAKOPOULOS, P. \& KAPLANIS, S. 2014. Comprehensive experience for indoor air quality assessment: a review on the determination of volatile organic compounds (VOCs). Journal of Physical Chemistry \& Biophysics, 2014. 
PAYNE, S. R. 2013. The production of a perceived restorativeness soundscape scale. Applied Acoustics, 74, 255-263.

PELLERIN, N. \& CANDAS, V. 2004. Effects of steady-state noise and temperature conditions on environmental perception and acceptability. Indoor air, 14, 129-136.

PÉREZ-LOMBARD, L., ORTIZ, J. \& POUT, C. 2008. A review on buildings energy consumption information. Energy and Buildings, 40, 394-398.

POTBHARE, V., SYAL, M., ARIF, M., KHALFAN, M. M. \& EGBU, C. 2009. Emergence of green building guidelines in developed countries and their impact on India. Journal of Engineering, Design and Technology, 7, 99-121.

PRASAD, S. 2004. Clarifying intentions: the design quality indicator. Building Research \& Information, 32, 548-551.

QUANG, T. N., HE, C., KNIBBS, L. D., DE DEAR, R. \& MORAWSKA, L. 2014. Co-optimisation of indoor environmental quality and energy consumption within urban office buildings. Energy and Buildings, 85, 225-234.

RAGETTE, F. 2003. Traditional domestic architecture of the Arab region, Edition Axel Menges.

REA, M., FIGUEIRO, M. \& BULLOUGH, J. 2002. Circadian photobiology: An emerging framework for lighting practice and research. Lighting Research and Technology, 34, 177-187.

REA, M. S. 2000. The IESNA lighting handbook: reference \& application.

REINHART, C. F. Effects of interior design on the daylight availability in open plan offices. 2002 ACEEE Summer Study on Energy Efficiency in Buildings, 2002. 309-322.

REINHART, C. F., MARDALEVIC, J. \& ROGERS, Z. 2006. Dynamic daylight performance metrics for sustainable building design. Leukos, 3, 7-31.

RIGGIN, R. 1984. Compendium of methods for the determination of toxic organic compounds in ambient air. Research Triangle Park, North Carolina: Battelle Columbus Labs., OH (USA).

ROBERTS, C. \& NEWELL, G. 2009. Developing a socially responsible property investment index for UK property companies. Journal of Property Investment \& Finance, 27, 511-521.

ROELOFSEN, P. 2002. The impact of office environments on employee performance: The design of the workplace as a strategy for productivity enhancement. Journal of Facilities Management, 1, 247-264.

ROELOFSEN, P. 2015. A computer model for the assessment of employee performance loss as a function of thermal discomfort or degree of heat stress. Intelligent Buildings International, 120.

ROMM, J. \& BROWNING, W. 1994. Greening the Building and the Bottom Line - Increasing productivity through energy-efficient design. Rocky Mountain Institute.

ROPER, K. O. \& JUNEJA, P. 2008. Distractions in the workplace revisited. Journal of Facilities Management, 6, 91-109.

RUBIN, A., COLLINS, B. \& TIBBOTT, R. 1978. Window blinds as potential energy saver-a case study, NBS Building Science Series, vol. 112. National Institute for Standards and Technology, Gaithersburg, MA, USA.

SEKHAR, S., GONG, N., THAM, K. W., CHEONG, K., MELIKOV, A. K., WYON, D. \& FANGER, P. O. 2005. Findings of personalized ventilation studies in a hot and humid climate. HVAC\&R Research, $11,603-620$.

SELKOWITZ, S. E. 1999. High performance glazing systems: architectural opportunities for the 21st century. Glass Processing Days, Tampere, Finland, 13-16.

SEPPÄNEN, O. \& FISK, W. 2002. Association of ventilation system type with SBS symptoms in office workers. Indoor Air, 12, 98-112.

SEPPÄNEN, O., FISK, W. \& MENDELL, M. 1999. Association of ventilation rates and CO2 concentrations with health and other responses in commercial and institutional buildings. Indoor air, 9, 226-252.

SEPPANEN, O., FISK, W. J. \& FAULKNER, D. 2003. Cost benefit analysis of the night-time ventilative cooling in office building. Lawrence Berkeley National Laboratory. 
SEPPÄNEN, O. A. \& FISK, W. 2006. Some quantitative relations between indoor environmental quality and work performance or health. Hvac\&R Research, 12, 957-973.

SHAHZAD, S., BRENNAN, J., THEODOSSOPOULOS, D., HUGHES, B. \& CALAUTIT, J. K. 2016. Energy and comfort in contemporary open plan and traditional personal offices. Applied Energy.

SHIN, S.-H. \& JO, W.-K. 2013. Longitudinal variations in indoor VOC concentrations after moving into new apartments and indoor source characterization. Environmental Science and Pollution Research, 20, 3696-3707.

SINGH, A., SYAL, M., GRADY, S. C. \& KORKMAZ, S. 2010. Effects of Green Buildings on Employee Health and Productivity. American Journal of Public Health, 100, 1665.

SIVAJI, A., SHOPIAN, S., NOR, Z. M., CHUAN, N.-K. \& BAHRI, S. 2013. Lighting does Matter: Preliminary Assessment on Office Workers. Procedia - Social and Behavioral Sciences, 97, 638-647.

SOFLAEE, F. \& SHOKOUHIAN, M. Natural cooling systems in sustainable traditional architecture of Iran. International Conference on Passive and Low Energy Cooling for the Built Environment, 2005.

SRIVASTAV, S. \& JONES, P. 2009. Use of traditional passive strategies to reduce the energy use and carbon emissions in modern dwellings. International Journal of Low-Carbon Technologies, 4, 141-149.

STALLWORTH JR, O. E. \& KLEINER, B. H. 1996. Recent developments in office design. Facilities, 14, 34-42.

STANSFELD, S. A. \& MATHESON, M. P. 2003. Noise pollution: non-auditory effects on health. British medical bulletin, 68, 243-257.

STEIN, B., REYNOLDS, J. S. \& MCGUINNESS, W. J. 1992. Mechanical and electrical equipment for buildings, J. Wiley \& Sons.

STOKOLS, D. \& SCHARF, T. 1990. Developing standardized tools for assessing employees' ratings of facility performance. ASTM special technical publication, 55-79.

STONE, N. J. 2001. DESIGNING EFFECTIVE STUDY ENVIRONMENTS. Journal of Environmental Psychology, 21, 179-190.

SULLIVAN, R., LEE, E., PAPAMICHAEL, K., RUBIN, M. \& SELKOWITZ, S. E. Effect of switching control strategies on the energy performance of electrochromic windows. Optical Materials Technology for Energy Efficiency and Solar Energy Conversion XIII, 1994. International Society for Optics and Photonics, 443-455.

SUNDSTROM, E., TOWN, J. P., RICE, R. W., OSBORN, D. P. \& BRILL, M. 1994. Office noise, satisfaction, and performance. Environment and Behavior, 26, 195-222.

SZCZUREK, A., MACIEJEWSKA, M., TEUERLE, M. \& WYŁOMAŃSKA, A. 2015. Method to characterize collective impact of factors on indoor air. Physica A: Statistical Mechanics and its Applications, 420, 190-199.

TANABE, S.-I., NISHIHARA, N. \& HANEDA, M. 2007. Indoor Temperature, Productivity, and Fatigue in Office Tasks. HVAC\&R Research, 13, 623-633.

TEICHMAN, K. Y., PERSILY, A. K. \& EMMERICH, S. J. 2015. Indoor air quality in high-performing building case studies: Got data? Science and Technology for the Built Environment, 21, 91-98.

TETLOW, R., BEAMAN, C., ELMUALIM, A. \& COULING, K. The impact of occupant behaviour on the variation between the design and in-use energy consumption of non-domestic buildings: An experimental approach. 3rd Annual TSBE EngD Conference Proceedings. University of Reading, 2012.

THAM, K. W., WARGOCKI, P. \& TAN, Y. F. 2015. Indoor environmental quality, occupant perception, prevalence of sick building syndrome symptoms, and sick leave in a Green Mark Platinumrated versus a non-Green Mark-rated building: A case study. Science and Technology for the Built Environment, 21, 35-44.

TOFTUM, J., LUND, S., KRISTIANSEN, J. \& CLAUSEN, G. Effect of open-plan office noise on occupant comfort and performance. 10th International Conference on Healthy Buildings, 2012. 
TSE, W. \& SO, A. T. 2007. The importance of human productivity to air-conditioning control in office environments. HVAC\&R Research, 13, 3-21.

TUOMAALA, P., HOLOPAINEN, R., PIIRA, K. \& AIRAKSINEN, M. 2013. Impact of individual characteristics such as age, gender, BMI and fitness on human thermal sensation. Proceedings of $B S, 13,26-28$.

US-EPA 1990. Compendium of Methods for the Determination of Air Pollutants in Indoor Air. In: LABORATORY, E. S. F. A. R. A. E. A. (ed.). North Carolina: Office of Research and Development, EPA.

US-EPA 1999. Compendium of Methods for the Determination of Toxic Organic Compounds in Ambient Air Second Edition. In: INFORMATION, C. F. E. (ed.). Environment Portection Agency.

US GREEN BUILDING COUNCIL 2004. Making the business case for high performance green buildings. US Green Building Council, Washington, DC.

VAN BOMMEL, W. \& VAN DEN BELD, G. 2004. Lighting for work: a review of visual and biological effects. Lighting Research and Technology, 36, 255-266.

VAN DER VOORDT, T. J. 2004. Productivity and employee satisfaction in flexible workplaces. Journal of Corporate Real Estate, 6, 133-148.

VEITCH, J. A., FARLEY, K. M. \& NEWSHAM, G. R. 2002. Environmental satisfaction in open-plan environments: 1 . Scale validation and methods.

VERNON, H. M. \& BEDFORD, T. 1926. A Physiological Study of the Ventilation and Heating in Certain Factories. Medical Research Council. Indust. Fatigue Res. Board. Rep.

VERNON, H. M. \& BEDFORD, T. 1930. A Study of Heating and Ventilation in Schools. Med. Res. Council, Indust. Health Res. Board (formerly Indust. Fatigue Res. Board) Rep.

VILNAI-YAVETZ, I., RAFAELI, A. \& YAACOV, C. S. 2005. Instrumentality, Aesthetics, and Symbolism of Office Design. Environment and Behavior, 37, 533-551.

WARD, V. \& HOLTHAM, C. 2000. The role of private and public spaces in knowledge management. victoria, 20, 1202.

WARGOCKI, P. 2000. The ffects of outdoor air supply in an office on perceived air quality, sick building syndrome (SBS) symptoms and producivity. Indoor air, 10, 222-236.

WARGOCKI, P., THAM, K., SEKHAR, S. \& CHEONG, D. Estimate of an economic benefit from investment in improved indoor air quality in an office building. 7th International Conference on Healthy Buildings 2003, 2003. 382-387.

WARGOCKI, P., WYON, D. P., SUNDELL, J., CLAUSEN, G. \& FANGER, P. 2000. The effects of outdoor air supply rate in an office on perceived air quality, sick building syndrome (SBS) symptoms and productivity. Indoor air, 10, 222-236.

WAY, M. 2006. Soft landings: A fresh scope of service that ensures users and clients get the best out of a new building. Journal of Facilities Management, 4, 23-39.

WAY, M. \& BORDASS, B. 2005. Making feedback and post-occupancy evaluation routine 2: Soft landings-involving design and building teams in improving performance. Building Research \& Information, 33, 353-360.

WHEELER, G. \& ALMEIDA, A. 2006. These Four Walls: The Real British Office. Creating the Productive Workplace, 357.

WHEELER, G., ALMEIDA, A. \& CLEMENTS-CROOME, D. 2006. Creating the Productive Workplace.

WOLKOFF, P. 2013a. Indoor air pollutants in office environments: assessment of comfort, health, and performance. Int J Hyg Environ Health, 216, 371-94.

WOLKOFF, P. 2013b. Indoor air pollutants in office environments: assessment of comfort, health, and performance. International journal of hygiene and environmental health, 216, 371-394.

WORLD GREEN BUILDING COUNCIL 2014. Health, Wellbeing \& Productivity in Offices. World Green Building Council.

WORLD HEALTH, O. 1982. Indoor air pollutants exposure and health effects report on a WHO meeting, Nordlingen, 8-11 June 1982. EURO reports and studies, 78. 
WORLD HEALTH ORGANIZATION 2005. WHO Air Quality Guidelines Global Update 2005: Report on a Working Group Meeting, Bonn, Germany, 18-20 October 2005, WHO Regional Office for Europe.

WOTTON, E. 1982. An investigation of the effects of windows and lighting in offices, Health and Welfare Canada.

WYON, D. 2004. The effects of indoor air quality on performance and productivity. Indoor air, 14, 92101.

YANG, I.-H. \& NAM, E.-J. 2010. Economic analysis of the daylight-linked lighting control system in office buildings. Solar Energy, 84, 1513-1525.

YILDIRIM, K., AKALIN-BASKAYA, A. \& CELEBI, M. 2007. The effects of window proximity, partition height, and gender on perceptions of open-plan offices. Journal of Environmental Psychology, 27, 154-165.

ZAGREUS, L., HUIZENGA, C., ARENS, E. \& LEHRER, D. 2004. Listening to the occupants: a Web-based indoor environmental quality survey. Indoor Air, 14, 65-74.

ZHAI, Y., ZHANG, H., ZHANG, Y., PASUT, W., ARENS, E. \& MENG, Q. 2013. Comfort under personally controlled air movement in warm and humid environments. Building and Environment, 65, 109-117.

ZHAI, Y., ZHANG, Y., ZHANG, H., PASUT, W., ARENS, E. \& MENG, Q. 2015. Human comfort and perceived air quality in warm and humid environments with ceiling fans. Building and Environment, 90, 178-185.

ZHANG, H., ARENS, E., KIM, D., BUCHBERGER, E., BAUMAN, F. \& HUIZENGA, C. 2010. Comfort, perceived air quality, and work performance in a low-power task-ambient conditioning system. Building and Environment, 45, 29-39.

ZHANG, Y. \& BARRETT, P. 2012a. Factors influencing occupants' blind-control behaviour in a naturally ventilated office building. Building and Environment, 54, 137-147.

ZHANG, Y. \& BARRETT, P. 2012b. Factors influencing the occupants' window opening behaviour in a naturally ventilated office building. Building and Environment, 50, 125-134.

ZHENG, G., JING, Y., HUANG, H. \& MA, P. Thermal Comfort and Indoor Air Quality of Task Ambient Air Conditioning in Modern Office Buildings. Information Management, Innovation Management and Industrial Engineering, 2009 International Conference on, 2009a. IEEE, 533-536.

ZHENG, G., JING, Y., HUANG, H. \& MA, P. 2009b. Thermal Comfort and Indoor Air Quality of Task Ambient Air Conditioning in Modern Office Buildings. 533-536. 